Portland State University

PDXScholar

$10-2-2019$

\title{
Remote Characterization of Dominant Wavelengths From Surface Folding on Lava Flows Using Lidar and Discrete Fourier Transform Analyses
}

\author{
Nicholas Deardorff \\ Indiana University of Pennsylvania \\ Adam M. Booth \\ Portland State University, boothad@pdx.edu \\ Katharine Cashman \\ University of Bristol
}

Follow this and additional works at: https://pdxscholar.library.pdx.edu/geology_fac

Part of the Geology Commons, and the Volcanology Commons

\section{Let us know how access to this document benefits you.}

\begin{abstract}
Citation Details
Deardorff, N., Booth, A., \& Cashman, K. (2019). Remote Characterization of Dominant Wavelengths From Surface Folding on Lava Flows Using Lidar and Discrete Fourier Transform Analyses. Geochemistry, Geophysics, Geosystems, 20(8), 3952-3970.
\end{abstract}

This Article is brought to you for free and open access. It has been accepted for inclusion in Geology Faculty Publications and Presentations by an authorized administrator of PDXScholar. Please contact us if we can make this document more accessible: pdxscholar@pdx.edu. 


\section{Geochemistry, Geophysics, Geosystems}

\author{
RESEARCH ARTICLE \\ 10.1029/2019GC008497 \\ Key Points: \\ - Discrete Fourier transform (DFT) \\ analyses can be used to extract \\ dominant wavelengths of lava flow \\ surface folds from digital terrain \\ models \\ - Average dominant wavelengths \\ determined through discrete Fourier \\ transform (DFT) analyses generally \\ increase with viscosity \\ - DFT power spectral densities \\ correlate with lava profile \\ roughness, and dominant fold \\ wavelength is closely related to lava \\ surface roughness
}

Supporting Information:

- Supporting Information S1

- Data Set S1

- Figure S1

Correspondence to:

N. Deardorff,

n.deardorff@iup.edu

Citation:

Deardorff, N., Booth, A., \& Cashman, K. (2019). Remote characterization of dominant wavelengths from surface folding on lava flows using lidar and discrete Fourier transform analyses. Geochemistry, Geophysics, Geosystems, 20, 3952-3970. https://doi.org/10.1029/ 2019GC008497

Received 10 JUN 2019

Accepted 12 JUL 2019

Accepted article online 24 JUL 2019

Published online 8 AUG 2019

\section{Remote Characterization of Dominant Wavelengths From Surface Folding on Lava Flows Using Lidar and Discrete Fourier Transform Analyses}

\author{
Nicholas Deardorff ${ }^{1}$ (D), Adam Booth ${ }^{2}$ iD, and Katharine Cashman ${ }^{3}$ iD \\ ${ }^{1}$ Department of Geoscience, Indiana University of Pennsylvania, Indiana, PA, USA, ${ }^{2}$ Department of Geology, Portland \\ State University, Portland, OR, USA, ${ }^{3}$ School of Earth Sciences, University of Bristol, Bristol, UK
}

\begin{abstract}
Surface folding is common in lava flows of all compositions and is believed to be due to changes in viscosity and flow velocity between the cooling crust and the more fluid flow interior. However, our understanding of the relationship between surface folding and flow rheology is incomplete. In this study we analyze digital terrain models of eight lava flows ranging in composition from basaltic andesite to rhyolite using a discrete Fourier transform analysis to quantitatively determine dominant surface fold wavelengths. Our discrete Fourier transform analyses show that each lava flow has multiple fold generations and that dominant wavelengths are more closely related to calculated effective viscosity than to lava composition. At our Oregon sites, average dominant wavelengths generally increase with viscosity $\left(r^{2}=0.68\right)$, and the correlation improves $\left(r^{2}=0.87\right)$ when expanded by including previously measured fold wavelengths and viscosities from the global database. However, there are a few exceptions to this positive trend where a few lava flows have lower or higher than expected dominant fold wavelengths, which we infer are due to secondary factors such as differences in eruption conditions (eruption rate, temperature, etc.). Additionally, over a 5 order of magnitude range in viscosity, there is significant overlap between the ranges of fold wavelengths, particularly from 10 to $20 \mathrm{~m}$, for lavas from basaltic andesite to rhyolite, making it difficult to determine a numeric correlation between surface folds and lava rheology that would allow remote characterization of lava.
\end{abstract}

Plain Language Summary Folding of the surface crust of lava flows is common and is believed to be due to the interior of the lava flow flowing more easily and quickly than the lava crust, which is much stiffer and more brittle. However, our understanding of the relationship between surface folding and how lava flows and deforms is incomplete. In this study we analyze three-dimensional digital models of the surfaces of lava flows over a range in composition. Our analyses look at patterns of periodicities within the lave surfaces, which can detect differences in roughness between lava flows as well as the size and distance between surface folds. Our findings show that typically lavas that are thick and sticky, flowing less easily, have larger fold wavelengths (distances between folds) and lavas that flow more easily have smaller fold wavelengths. This type of analysis provides a versatile tool for characterizing lava flows without ever visiting the location physically and has significant implications for possible future analyses of volcanic terrains on Earth in hard to reach locations and on other planets and moons.

\section{Introduction}

Traditionally, lava flows have been studied primarily in the field with manual measurements, mapping, and sample collection, with a focus on active eruptions at particularly productive mafic volcanoes (e.g., Hawaii, USA, and Mt. Etna, Italy). The focus on mafic eruptions has led to flow parameters (mass eruption rate, flow duration, etc.) and rheology (i.e., viscosity) for basaltic lava flows being very well constrained (e.g., Calvari et al., 2003; Guest et al., 1987; Hon et al., 1994; Kauahikaua et al., 1998; Lipman \& Banks, 1987; Harry Pinkerton \& Wilson, 1994; Wadge et al., 1975; Walker, 1971), while emplacement conditions for flows of intermediate and silica-rich compositions are less well constrained (Deardorff \& Cashman, 2012; Tuffen et al., 2013). The paucity of data on more evolved lavas is largely due to infrequent eruptions and the inherent difficulty in collecting morphologic measurements, due to flow margins tens of meters high and block sizes decimeters to meters in diameter. Few intermediate to silica-rich lava flows have been observed by scientists during emplacement, including Arenal, Costa Rica (andesite: A Borgia \& Linneman, 1990;
(C)2019. American Geophysical Union. All Rights Reserved. 
Andrea Borgia et al., 1983; Cigolini et al., 1984); Lonquimay, Chile (andesite: Naranjo et al., 1992); Santiaguito, Guatemala (dacite: Harris et al., 2003; Rose, 1973); Mount St. Helens, USA (dacite: Sherrod et al., 2008; Swanson \& Holcomb, 1990; Vallance et al., 2008); Kameni Islands, Greece (dacite: Pyle \& Elliott, 2006); Chaitén, Chile (rhyolite: Major \& Lara, 2013; Pallister et al., 2013); and Cordón Caulle, Chile (rhyolite: Tuffen et al., 2013). Evolved lavas occur primarily within volcanic arc settings and are typically located at relatively high elevations, often in remote locations.

Advances in new technology (e.g., satellite, aerial, and ground-based remote sensing techniques) have drastically increased our ability to quantitatively characterize lava flows in the last few decades (K. V. Cashman et al., 2013; Katharine V Cashman \& Sparks, 2013 and refs therein). Airborne Laser Swath Mapping (e.g., lidar [light detection and ranging]) is particularly useful in quantifying lava morphologies as it produces high-resolution ( $<1 \mathrm{~m}$ horizontal) and high-precision (centimeter to decimeter vertical) three-dimensional digital data, from which vegetation can be removed via filtering. Three-dimensional digital terrain models (DTMs) derived from lidar point clouds can be used to extract accurate morphologic measurements from emplaced lava flows. This is particularly useful on large blocky lava flows, typically of more evolved compositions, where field measurements are difficult or impossible. Simple morphologic measurements can then be used in numerical models to determine effusion rates and emplacement durations for prehistoric lava flows (Deardorff \& Cashman, 2012). Such numerical models often require assumptions on lava rheology, particularly viscosity, and knowledge of bulk composition, requiring manual sample collection. Therefore, truly remote (i.e., inaccessible) lava flows would require additional assumptions on composition in similar numerical modeling, increasing the potential error in such analyses.

In this study, we use lidar data from eight lava flows over a range of compositions (basaltic andesite to rhyolite) in the central Oregon High Cascades to analyze surface features, specifically the dominant wavelengths of surface folds, and their relationship to the composition and rheology of the flows. For our analyses we apply a discrete Fourier transform (DFT) analysis to along-channel profiles extracted from lidar-derived DTMs to objectively determine dominant wavelengths (the most prominent and periodic surface folds) for each flow. We define "dominant wavelengths" as topographic wavelengths, measured with the Fourier transform, with spectral power greater than that of a power law spectrum at the 95\% confidence level. We focused our analyses on more evolved lavas to fill the knowledge gap described above, and because basaltic lavas often produce surface folding on a smaller scale than is detectable using DTMs gridded at 1-m horizontal resolution. We then compare our results to published measurements from a wide range of flow types (basalt to rhyolite) to evaluate the potential use of flow surface morphologies for inferring the composition of remote lava flows, with the potential for use on extraterrestrial lava flows (e.g., Mars and Venus). While we primarily focus our analyses on lava flows in Oregon, the techniques used in this study can be used to remotely characterize any lava flow on Earth or other planetary bodies for which DTMs are available.

\subsection{Area of Study}

We selected the central Oregon Cascades as the study area for this project due to the wide range in accessible lava compositions over a relatively small area and the availability of lidar-derived high resolution DTMs (available through the Oregon Lidar Consortium). The central Oregon Cascades has produced volcanic deposits over the past 35 million years ranging from basalt $\left(<52 \mathrm{wt} \% \mathrm{SiO}_{2}\right)$ to rhyolite $\left(\geq 72 \mathrm{wt} \% \mathrm{SiO}_{2}\right)$ and consisting of lava flows, pyroclastic flow deposits, and tephra fall deposits (Sherrod et al., 2004).

Our study is focused primarily around the Three Sisters volcanic complex and Newberry Volcano within the Deschutes National Forest and near Bend, OR (Figure 1). We have selected eight flows ranging in composition from $\sim 52$ to $73.5 \mathrm{wt} \% \mathrm{SiO}_{2}$ (see Table 1 for compositions, references, and ages) that are relatively young (mostly <7ka) and mostly unvegetated. Symbols (e.g., Lava Butte [LB]) are listed in Table 1. Lava flows $>7,700 y e a r s$ old in the area are blanketed by Mazama ash from the catastrophic eruption that produced the Crater Lake Caldera, potentially muting or partially obscuring their fold morphology. The only flow used in this study older than the Mazama eruption is Kokostick Butte (27.3 $\pm 2.6 \mathrm{ka}$; Fierstein et al., 2011), chosen as the best preserved dacite lava flow in the study area. All other flows used in this study are uncovered and only very lightly vegetated. 


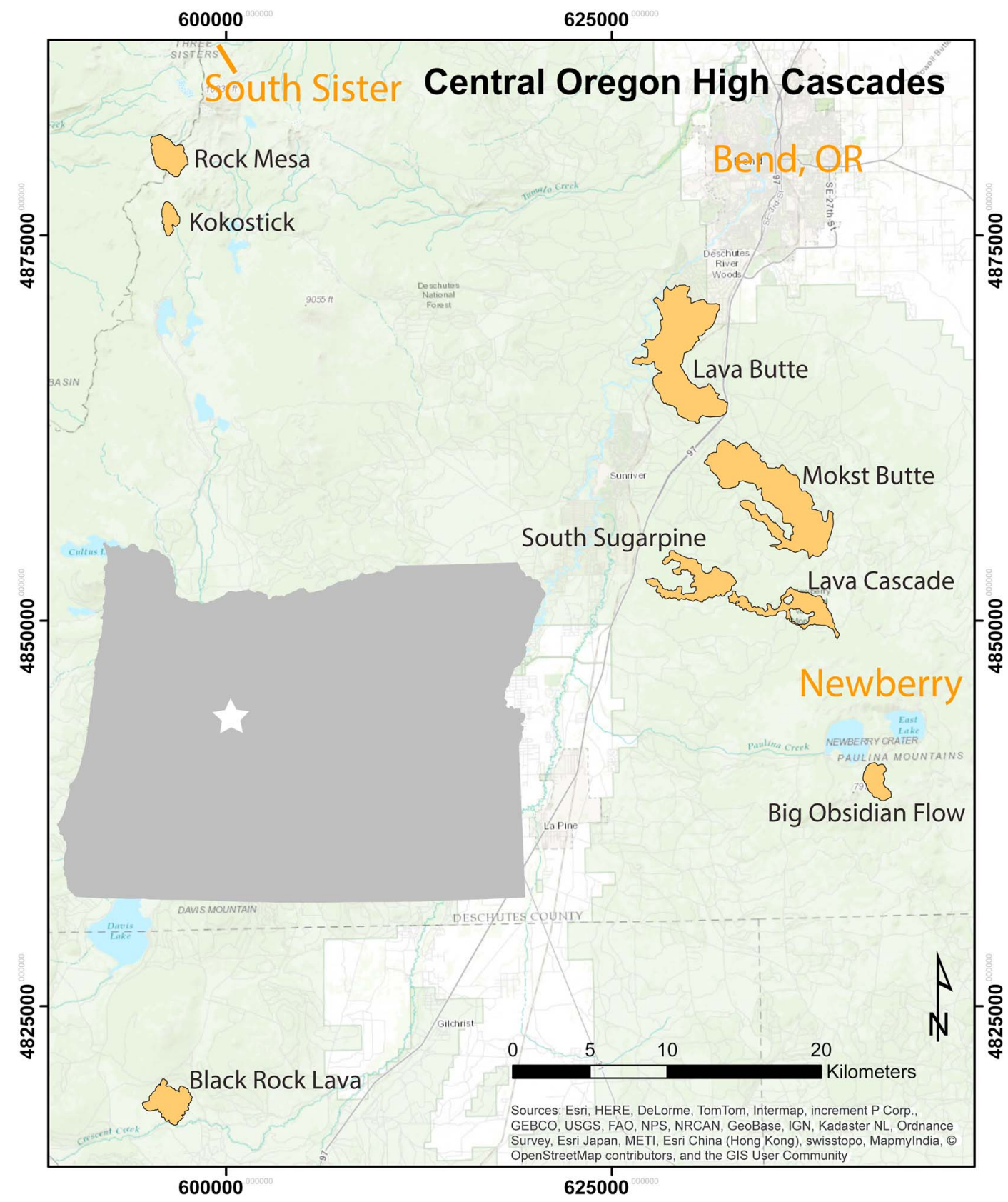

Figure 1. Locations of the lava flows analyzed in this study are depicted in orange. Lava flows are all located in the central Oregon High Cascades (star on insert) either on the south flank of the southernmost peak of the Three Sisters volcanic complex, in Newberry volcano, along the Northwest Rift Zone on the north flank of Newberry, or south of the Wickiup Reservoir). Coordinate system is NAD 1983 UTM zone 10N.

\subsection{Lava Surface Folds}

The surface of lava flows is commonly folded into arcuate ridges, bent such that the convex ridges point down flow (Figure 2a). Surface folding is common in lava flows of all compositions, from basalt (i.e., ropy pahoehoe; $<52 \mathrm{wt} \% \mathrm{SiO}_{2}$ ) to rhyolite flows $\left(>69 \mathrm{wt} \% \mathrm{SiO}_{2}\right)$, and is believed to be due to changes in viscosity and flow velocity between the cooling crust (solidified, brittle surface of flow) and the more fluid flow interior. Surface folds record the dynamics of flow emplacement and are formed by the competition between the fluid processes driving the flow (controlled primarily by lava flux and rheology) and the restraining presence of a growing (and confining) crust (e.g., Applegarth et al., 2010; Griffiths, 2000). Surface folds have been interpreted as compression of the advancing flow against a solidifying crust (J. Fink, 1980; J. H. Fink \& 
Table 1

Compositional Data, Age, Dominant Wavelengths, Crystallinities, and Calculated Viscosities for Lava Flows in This Study

\begin{tabular}{|c|c|c|c|c|c|c|c|c|}
\hline Lava flow (symbol) & $\begin{array}{l}\text { South Sugarpine } \\
\text { (SSP) }\end{array}$ & $\begin{array}{l}\text { Lava Butte } \\
\quad \text { (LB) }\end{array}$ & $\begin{array}{c}\text { Lava } \\
\text { Cascade } \\
\text { (LC) }\end{array}$ & $\begin{array}{l}\text { Mokst } \\
\text { Butte } \\
\text { (MB) }\end{array}$ & $\begin{array}{l}\text { Black Rock } \\
\text { Lava-Hamner } \\
\text { Butte (BRL) }\end{array}$ & $\begin{array}{l}\text { Kokostick } \\
\text { Butte (KB) }\end{array}$ & $\begin{array}{l}\text { Big Obsidian } \\
\text { Flow (BO) }\end{array}$ & $\begin{array}{l}\text { Rock } \\
\text { Mesa } \\
(\mathrm{RM})\end{array}$ \\
\hline \multicolumn{9}{|l|}{ Major elements wt $\%$} \\
\hline $\mathrm{SiO}_{2}$ & 52.72 & 55.83 & 56.46 & 57.61 & 58.06 & $63.5-63.1^{\mathrm{c}}$ & $73.24^{\mathrm{fg}}$, & 74.04 \\
\hline $\mathrm{TiO}_{2}$ & 1.36 & 1.130 & 1.25 & 1.25 & 0.85 & & 0.22 & 0.278 \\
\hline $\mathrm{Al}_{2} \mathrm{O}_{3}$ & 17.03 & 17.08 & 16.26 & 15.81 & 18.01 & & 14.20 & 13.87 \\
\hline $\mathrm{FeO}^{*}$ & 8.84 & 7.55 & 7.60 & 7.95 & 6.19 & & 2.03 & 1.85 \\
\hline $\mathrm{MnO}$ & 0.16 & 0.136 & 0.14 & 0.14 & 0.11 & & 0.06 & 0.046 \\
\hline $\mathrm{MgO}$ & 5.73 & 4.86 & 4.00 & 4.26 & 4.34 & & 0.19 & 0.46 \\
\hline $\mathrm{CaO}$ & 9.45 & 7.95 & 7.24 & 7.23 & 7.26 & & 1.12 & 1.68 \\
\hline $\mathrm{Na}_{2} \mathrm{O}$ & 3.64 & 3.93 & 4.14 & 3.92 & 3.91 & & 5.22 & 4.30 \\
\hline $\mathrm{K}_{2} \mathrm{O}$ & 0.78 & 1.29 & 1.46 & 1.63 & 1.06 & & 4.09 & 3.41 \\
\hline $\mathrm{P}_{2} \mathrm{O}_{5}$ & 0.28 & 0.244 & 0.28 & 0.20 & 0.21 & & 0.27 & 0.058 \\
\hline Age of flow & $\begin{array}{c}\sim 7,000 \mathrm{a} \mathrm{BP} \mathrm{a}^{\mathrm{a}} \\
6927 \pm 300 \mathrm{a} \mathrm{BP}\end{array}$ & $\sim 7,000 \mathrm{a} \mathrm{BP}{ }^{\mathrm{a}}$ & $\sim 7,000 \mathrm{a} \mathrm{BP}{ }^{\mathrm{a}}$ & $\sim 7,000 \mathrm{a} \mathrm{BP}{ }^{\mathrm{a}}$ & $5,451 \pm 307 a \mathrm{BP}^{\mathrm{b}}$ & $27.3 \pm 2.6 \mathrm{ka} \mathrm{BP}^{\mathrm{c}}$ & $\sim 1,300 \mathrm{a} \mathrm{BP}{ }^{\mathrm{e}}$ & $<2,500 \mathrm{a} \mathrm{BP}{ }^{\mathrm{d}}$ \\
\hline Dominant wavelengths (m) & $11,15,18,23$ & $\begin{array}{c}9,11,14-15 \\
18,24\end{array}$ & $\begin{array}{c}7,8,13 \\
17,19\end{array}$ & $\begin{array}{l}9,16,23 \\
26,33,45\end{array}$ & $\begin{array}{c}14,16,19-20 \\
24,34,77\end{array}$ & $3,30,38$ & $\begin{array}{l}2-3,8,10,13 \\
15,19,24,33\end{array}$ & $2,37,63,91$ \\
\hline $\begin{array}{l}\text { Crystallinity } \\
\quad \text { (BSE; Petrologic scope) }\end{array}$ & $32 \%$ & $47 \%$ & $3 \%$ & $30 \%$ & $40 \%$ & $17-23 \%^{\mathrm{c}}$ & $3.7 \%$ & $25 \%$ \\
\hline $\begin{array}{l}\text { Eruption liquidus } \\
\text { temperature }\left({ }^{\circ} \mathrm{C}\right) \\
\text { calculated using } \text { MELTS }^{\mathrm{g}},\end{array}$ & $1,193.46$ & $1,179.39$ & $1,172.75$ & $1,163.57$ & $1,188.77$ & N/A & $1,071.58$ & $1,058.11$ \\
\hline $\begin{array}{l}\text { Viscosity - Pa s } \\
\quad \text { (after Pinkerton \& } \\
\text { Stevenson, 1992) }\end{array}$ & 423 & 4,152 & 550 & 2,331 & 5,287 & N/A & $1,454,623$ & $9,049,271$ \\
\hline
\end{tabular}

Note. Compositional data for SSP, MB, and BRL are averages from multiple XRF analyses conducted through this study. LB, LC, and RM are analyses from just one sample each, not an average. $\mathrm{BO}$ and $\mathrm{KB}$ compositions are referenced by superscript numbers next to their $\mathrm{SiO}_{2}$ values. Uncertainty of viscosity calculations is within 1 order of magnitude. N/A, not available. Regarding Crystallinity, bold values were determined using backscatter electron images from a scanning electron microscope, while the italicized values were determined using images from a petrologic microscope. Remaining crystallinity values are referenced values from the literature.

${ }^{a}$ MckKay et al.(2009) and MacLeod et al. (1995). $\quad{ }^{b}$ MacLeod and Sherrod (1992). $\quad{ }^{c}$ Fierstein et al. (2011). $\quad{ }^{d}$ Fierstein et al. (2011) and Scott (1987). $\quad{ }^{e}$ Jensen et al. (2009). ${ }^{\mathrm{f}}$ Murase and McBirney (1973). ${ }^{\mathrm{g}}$ Asimow and Ghiorso (1998). ${ }^{\mathrm{h}}$ Ghiorso and Sack (1995).

Fletcher, 1978). However, folds often initiate near eruptive vents and are well developed in most lava channels (e.g., Pyle \& Elliott, 2006), which suggests that at least some folds may form because of lateral extension within the channel (Smith \& Houston, 1994). Alternatively, the surface folds may form when fluid traction along the base of the higher viscosity lava surface creates enough instability to induce buckling (Slim et al., 2009). Here the interior must travel at higher velocity than the higher viscosity surface to induce shear, but a flow constriction is not required for buckling to occur. The purpose of this study is not to extend previous studies on the processes of surface fold formation but to identify and quantify surface fold wavelengths remotely and determine their relation to lava composition and rheology.

In theory, the geometry of flow surface folds can be used to constrain the thickness and viscosity of the folding layer (from the fold wavelength) and the compressional stress (from the fold amplitude; e.g., J. H. Fink \& Fletcher, 1978; Gregg et al., 1998). Crustal thickness is controlled primarily by lava composition and extent of cooling. Less evolved (e.g., mafic) flows, erupting at higher temperatures and effusion rates than evolved lavas, will initially produce thin crusts that may develop into small fold wavelengths. As a flow cools, viscosity increases, and the crust thickens, which may produce additional generations of folding with increasingly greater wavelengths (J. H. Fink \& Fletcher, 1978; Gregg et al., 1998). Lavas of more evolved compositions (higher silica content) advance more slowly and have thicker crusts, which should generate surface folds with larger wavelengths, and may still produce multiple fold generations as the crust thickens.

Lava viscosity is partially controlled by crystallinity, which can vary significantly between lava compositions and tectonic settings. While phenocrysts and microphenocrysts form deeper within the crust, microlites may form during magma ascent or emplacement. Mafic lavas often erupt close to their liquidus temperatures with relatively low $\mathrm{H}_{2} \mathrm{O}$ contents and cool and crystallize during emplacement. In Hawaii syneruption 

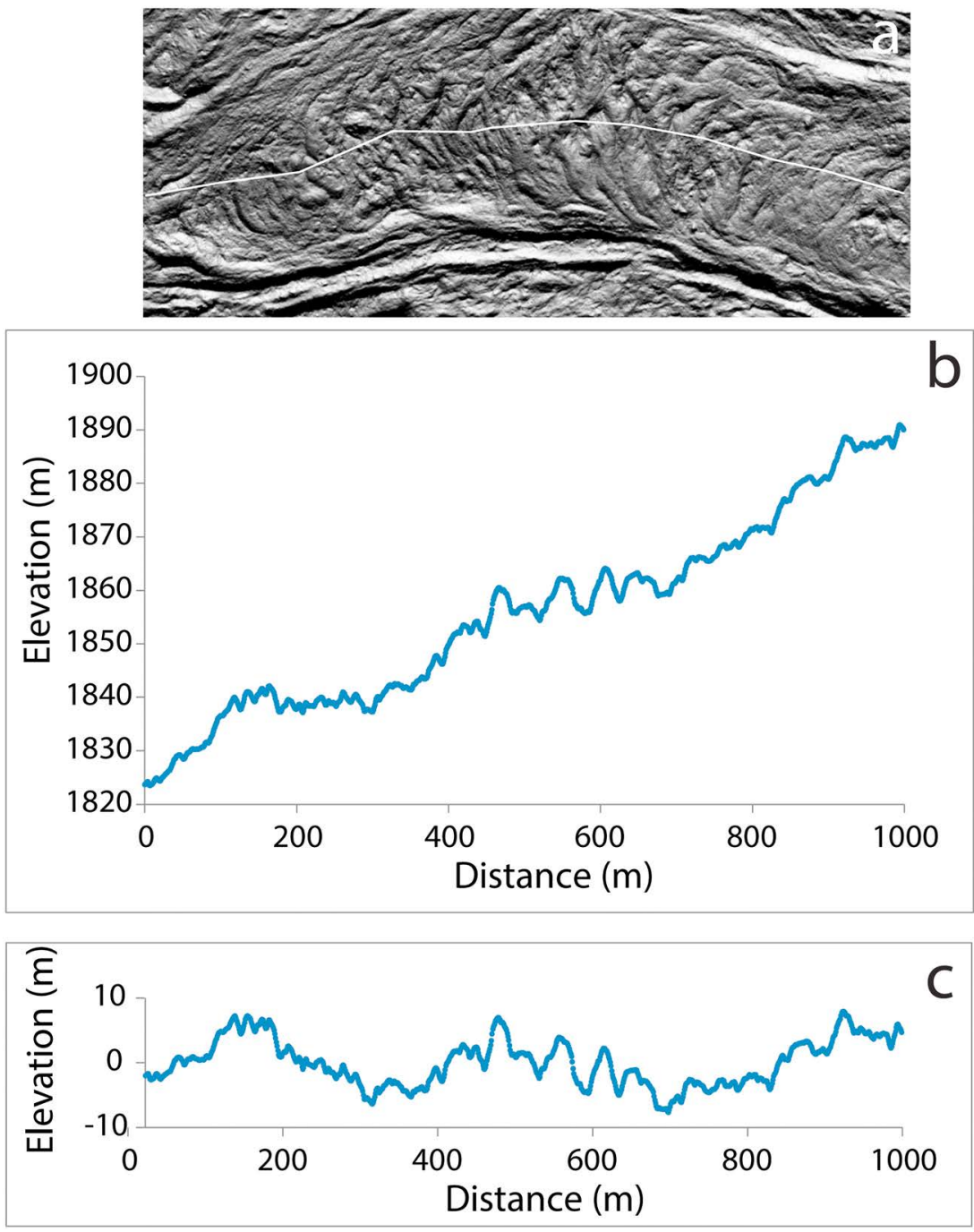

Figure 2. Example 1,000-m along-channel profile. (a) Lidar digital terrain model of surface folds within a well-channelized lava flow. The white line represents the location of 1,000-m-long profile from which the elevation data were extracted. (b) Plot of extracted elevation data showing pronounced surface folds at multiple wavelengths. (c) Detrended elevation profile from (b) used in discrete Fourier transform analyses. Note that the large-scale rise and fall of profile (c) is due to changes in slope observed in (b). A small window size $(\leq 300 \mathrm{~m})$ for the discrete Fourier transform analyses was chosen to avoid detection of such large-scale features, unrelated to surface folding.

crystallization dramatically changes both the rheology and surface morphology (converting from pahoehoe to a'a) through increasing shear rate (Soule \& Cashman, 2005). Volcanic arc magmas, in contrast, are $\mathrm{H}_{2} \mathrm{O}$ rich and typically more evolved, often experiencing extensive decompression-driven crystallization during magma ascent (e.g., Blundy \& Cashman, 2005; K. Cashman \& Blundy, 2000; Geschwind \& Rutherford, 1995; Hammer \& Rutherford, 2002). Increased crystallinities will increase magma viscosity but not necessarily affect bulk composition of a lava flow. Therefore, although magmas of more evolved compositions should have thicker crusts and produce larger surface fold wavelengths, due to variability in crystallinities between magmas of similar compositions, composition alone may not directly correlate to resulting surface fold wavelengths.

A detailed comparison of lava flow viscosity with surface fold wavelengths and amplitudes has not been accomplished. In fact, very few surface fold wavelengths of lava flows have been reported in the literature. In this study we use a common digital signal processing technique, DFT analysis, to remotely quantify surface fold wavelengths of eight lava flows by analyzing lava surface profiles extracted from high 
resolution lidar DTMs. We then compare dominant fold wavelengths with lava composition and viscosity. The wavelengths of surface folds should scale with crustal thickness and flow viscosity, which depend on effusion rate and lava composition. However, there is not currently a numeric model that directly relates surface fold wavelengths with lava rheology.

\section{Methods}

\subsection{Discrete Fourier Transforms}

To determine the characteristic scale of prominent surface folds, we extracted 500- or 1,000-m along-channel profiles at 1-m sample intervals from lidar-derived DTMs gridded at 1-m horizontal resolution in ArcGIS. Profiles were selected from segments of pronounced surface folds (Figures $2 \mathrm{a}$ and $2 \mathrm{~b}$ ) from eight lava flows of varying compositions. About 500-m profiles were chosen for shorter or confined segments of folding, and 1,000-m profiles were used for all other segments. All profile segments used in this study are available in Supporting Information S1. All lava profile elevations were detrended by subtracting the best fit line so their average elevation and slope were both zero (Figure 2c). This reduces the effect of large steps in profile elevation at either end of the profile on the spectral analyses and eliminates the overall first-order trend (slope) of the profile. All adjusted profiles were then analyzed using the DFT, consisting of an averaged modified periodogram.

Our detailed analyses of the surface folds measured the characteristic wavelengths (defined as the distance from crest to crest between folds in the direction perpendicular to the ridge crests) for each representative profile by one-dimensional (1-D) DFT analysis (Figure 3a), which can be used to determine the meansquared amplitude and spatial scale (wavelength) of periodic and quasiperiodic surface features (Booth et al., 2009; Perron et al., 2008; Rayner \& Golledge, 1972). A DFT of a 1-D data set $z(x)$ consisting of $N_{x}$ measurements spaced at an even interval $\Delta x$ is written as

$$
Z\left(k_{x}\right)=\sum_{m=0}^{N_{x}-1} z(m \Delta x) e^{-2 \pi i\left(\frac{k_{x} m}{N_{x}}\right)}
$$

where $k_{x}$ is the wavenumber in the $x$ direction, $m$ is the index in the $z$ profile $(x=m \Delta x), \Delta x$ is the grid spacing, and $i$ is the imaginary number $\sqrt{-1}$ (Priestley, 1981). For efficiency of the DFT algorithm, profiles were padded with zeros on both ends so that the profile length was increased to the next highest power of 2 . The power spectrum for the DFT analysis is estimated using the power spectral density (PSD):

$$
P_{\mathrm{PSD}}\left(k_{x}\right)=\left\{\frac{\Delta x}{N_{x}}\left|Z\left(k_{x}\right)\right|^{2}\right\}
$$

where the brackets indicate the magnitude, and which has units of amplitude squared per unit $\mathrm{x}$ frequency ( $\mathrm{m}^{2} /$ frequency). This DFT analysis and all calculations were completed using Matlab version R2015a (MathWorks, Inc.). An example of our Matlab code used for DFT analyses of the lava flow profiles is provided in Supporting Information S2.

Our DFT analysis measured the PSD of the input profile (elevation with distance) using Welch's PSD estimate (pwelch) with a 200 m (most flows SS, Lava Cascade [LC], LB, Mokst Butte [MB], and Big Obsidian Flow [BO]) or 300m (Black Rock Lava-Hamner Butte [BRL], Kokostick Butte [KB], and Rock Mesa [RM]) Hamming window with $50 \%$ overlap. Window size was chosen to (1) minimize the local slope effects, which typically vary over several hundred meters, and (2) to produce the most defined spectral peaks over the range of frequencies observed. The PSD analyses produce 1-D power spectra, which describe how the amplitude of lava surface topography varies over a range of spatial scales (wavelength), or equivalently, over a range of spatial frequencies (Figure 3a). DFT spatial frequencies have units of $\mathrm{m}^{-1}$, the inverse of which provides fold wavelengths $(K)$ in meters. To statistically identify characteristic wavelengths of lava surface morphology, the 1-D power spectra were normalized by dividing representative segments by their best fit power law trendline, making deviations from the power law (background spectra) more apparent (Figure 3b). Rednoise background spectra were also fit to each profile; however, they do not fit the power spectra well at intermediate and high frequencies. Therefore, power law trendlines provided the best fit background 

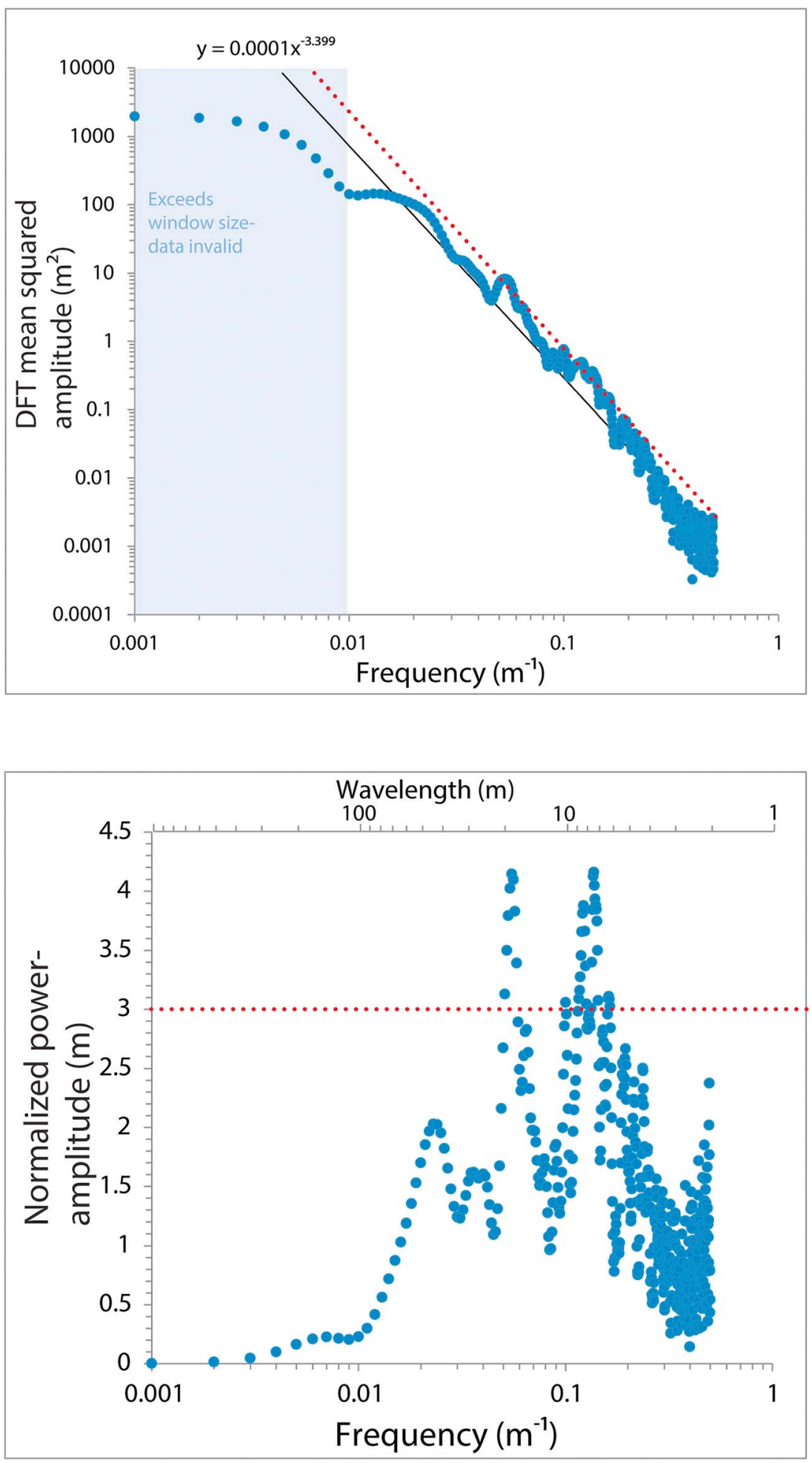

Figure 3. (a) Example 1-D array of spectral density derived from our discrete Fourier transform (DFT) power spectral density analyses using the lava profile from Figure 2. Note the strong deviations (bumps) from the power law trendline (solid black line), which represent dominant wavelengths of surface folds that exceed the $95 \%$ confidence (dotted red line). The shaded region represents data that exceeds the DFT analysis window size, not included in our discussion. (b) Normalized power spectral density, allowing easier viewing of dominant wavelengths that exceed the 95\% confidence. 
spectra. Examples of the power spectral densities and normalized spectra for each lava flow analyzed are shown in Supporting Information S3.

Deviations of the power spectra above the power law trendline objectively define characteristic morphologic features. Those with at least $95 \%$ significance have peaks three times greater than the background power law spectra (Torrence \& Compo, 1998; represented by red dotted lines in Figures 3a and 3b and S3 in the supporting information). Although PSD has units of amplitude squared per unit frequency ( $\mathrm{m}^{2} /$ frequency), it does not directly represent the amplitude of the lava surface fold waveforms that one would measure in the field. This is because the folds are neither exactly periodic nor perfectly sinusoidal, such that their spectral power is spread out over a range of wavelengths. PSD quantifies the contribution of each discrete wavelength sampled to the total variance of the detrended profile.

\subsection{Field Samples}

Rock samples were collected from seven lava flows (none from $\mathrm{KB}$ ) of varying compositions in the central Oregon Cascades. Samples were sent to the GeoAnalytical Lab at Washington State University for ThermoARL X-Ray Fluorescence spectrometer analysis of all major and trace elements. This data set was supplemented by bulk composition analyses within the literature. Geochemical data are reported in Table 1. Thin sections were produced for petrographic analyses and scanning electron microscopy. Petrographic microscope and scanning electron microscopy back scatter electron images were used to quantify crystallinities $(\phi)$ using ImageJ software. Many of the lava samples collected were completely crystalline, having continued crystallization synemplacement and postemplacement. While lava may crystallize during and postemplacement, tephra is rapidly quenched by air and can provide an estimate of microlite crystallinity at the time of the eruption. Therefore, we analyzed tephra samples from South Sugarpine (SSP), LB, MB, and BRL, assuming that the tephra collected were immediately quenched, ceasing crystallization upon eruption. No tephra was collected for LC, BO, and RM. For these flows, thin sections of the lava flows were analyzed, in which we separated dual populations of crystals, including only those $\geq 30-100 \mu \mathrm{m}$ in length (minimum accepted size varied for each lava flow) were considered, ignoring all groundmass microlites $(<30 \mu \mathrm{m})$. While this method likely produced minimum possible crystallinities for LC, the BO and RM values are likely representative as rhyolites typically have limited decompression and syneruption crystallization (K. Cashman \& Rust, 2016).

\subsection{Lava Viscosities}

The primary goal of this study is to link surface features (i.e., dominant wavelengths of folds) to lava composition or rheology, such as viscosity. The lava flows of this study were not observed during emplacement. Therefore, we calculated lava viscosities $(\eta)$ using the numeric model of Pinkerton and Stevenson (1992) using the known variables, composition, and crystallinity. In the equation

$$
\eta(\phi)=\eta_{f} e^{\left\{\left[2.5+\left(\frac{\phi}{\phi_{\max }-\phi}\right)^{0.48}\right] \frac{\phi}{\phi_{\max }}\right\}}
$$

$\phi$ is the measured crystallinity (considering only phenocrysts and microphenocrysts $\geq 30-100 \mu \mathrm{m}$ ) and $\phi_{\max }$ is an assumed maximum crystallinity (0.7) above which flow ceases/viscosity becomes infinite (Gay et al., 1969; Marsh, 1981; H. Pinkerton \& Stevenson, 1992). $\eta_{f}$ is the fluid viscosity calculated as a function of composition and temperature (after Shaw, 1972), using

$$
\ln \left(\eta_{f}\right)=s\left(\frac{10^{4}}{T}\right)-s c_{T}+c_{\eta}
$$

where $T$ is eruption liquidus temperature (calculated using MELTS [Asimow \& Ghiorso, 1998; Ghiorso \& Sack, 1995]), s is a characteristic slope for $\eta$-T relationship (calculated using composition), and $c_{T}$ and $c_{\eta}$ are T- and $\eta$-dependent constants. Due to uncertainties associated with unknown eruption conditions, particularly eruption temperature, during emplacement of the lava, viscosities calculated in this manner can be estimated to within an order of magnitude (H. Pinkerton \& Stevenson, 1992). Viscosities calculated using the Pinkerton and Stevenson (1992) method should be considered minima as crystallinities, and resulting viscosities, will increase during lava emplacement as lava cools and groundmass crystallinity increases. 


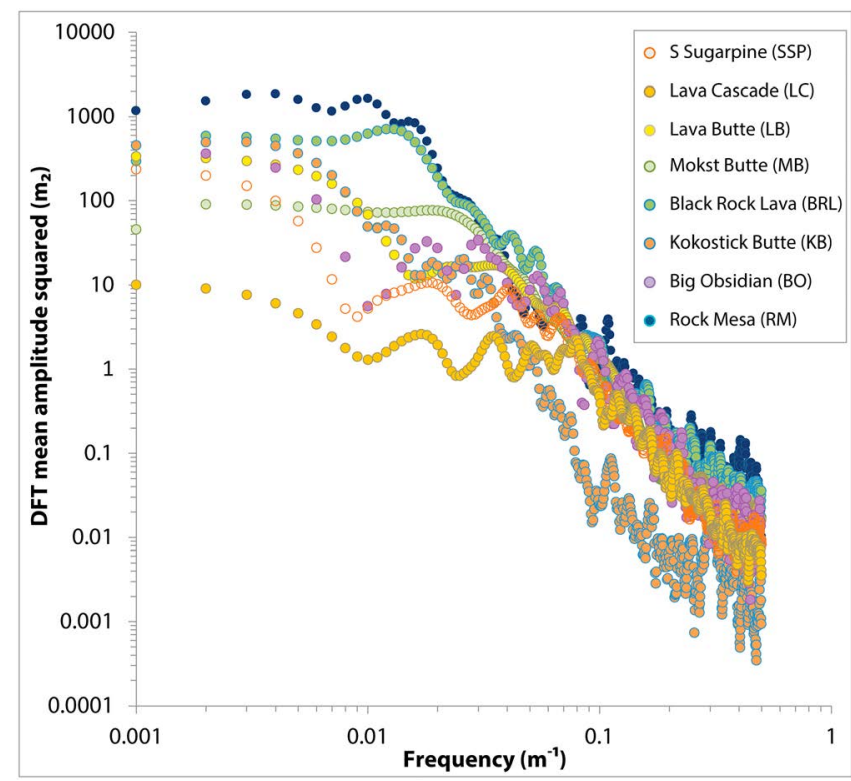

Figure 4. Representative discrete Fourier transform (DFT) spectral density arrays for each lava flow analyzed in this study. Low spectral density signals have rapid fluctuations at high frequencies (above $0.2 \mathrm{~m}^{-1}$ ) but smooth out to form broad peaks at intermediate and low frequencies. The power spectral density arrays vary between lava flows and, to a lesser extent, from one lava profile to the next from the same lava flow (not shown in figure). The power spectra of Kokostick Butte lies below the spectra of all other flows at intermediate and high frequencies, likely due to blanketing of Mazama ash filling in troughs and depressions and reducing the periodicities detected.

\subsubsection{A Note on Viscosity Calculations}

The authors recognize the Pinkerton and Stevenson (1992) model is dated and there are numerous more recent, and possibly more robust, viscosity calculations, including (but not limited to) Costa et al. (2009); Caricchi et al. (2007); Giordano et al. (2008); Harris and Allen (2008); and Mader et al. (2013). We have chosen to use the Pinkerton and Stevenson model due to its extensive use in the literature over the last few decades. In section 4.1 we compare our results to those recorded in the literature and many use the same viscosity calculations. We therefore opted to use the more dated model in order to produce a more direct comparison. Our approach of comparing dominant surface fold wavelengths with calculated viscosities would work using any viscosity numerical model.

\section{Results}

\subsection{DFT Surface Analysis}

DFT analysis of 500- and 1,000-m profiles provide a measure of spectral power over a range of frequencies. The spectral power of the analyzed lava profiles decrease with increased frequency, as expected for landforms (Perron et al., 2008). A relatively flat lava profile with no topographic features (other than block sizes) would follow this trend (the power law trendline) without significant deviations. Prominent morphological features (such as surface folds, tumuli, and extensional cracks) produce deviations from the trend in the form of vertical fluctuations at intermediate frequencies (Figure 3). The underlying assumption is that surface folding is quasi-periodic such that it concentrates spectral power over a narrow range of frequencies, and other features, such as extensional cracking and tumuli, are not, which allows us to extract the dominant wavelengths of folding by looking for peaks in the power spectra. Because the lava surface features are not perfectly sinusoidal or periodic, the vertical fluctuations tend to form somewhat broad, rather than sharp, peaks, particularly at longer wavelengths. We refer to spectral peaks that rise above the 95\% significance level (red dotted line, Figure 3) as dominant wavelengths representing the most prominent and periodic surface folds. We confine our analysis of dominant wavelengths to frequencies of $0.5-0.01 \mathrm{~m}^{-1}(\lambda=2-100 \mathrm{~m})$ for DFT analyses using $200-\mathrm{m}$ windows and $0.5-0.0067 \mathrm{~m}^{-1}(\lambda=$ $2-\sim 150 \mathrm{~m}$ ) for analyses using 300-m windows. Wavelengths longer than these cutoff values (lower frequencies) deviate from power law scaling and are possibly influenced by the zero padding on both ends of the window.

In all flows, low spectral power at high frequencies are noisy above $0.2 \mathrm{~m}^{-1}(\lambda<5 \mathrm{~m})$, smoothing out (less noisy) with decreased frequency. The lowest spectral power values lie at frequencies $\sim 0.3-0.5 \mathrm{~m}^{-1}$ and vary among lava flows (Figure 4), and between some profiles from the same flow, suggesting that the signal is not a gridding artifact. Instead, the noisy, high-frequency signals may be due to surface roughness or the inherent uncertainty in the lidar data (discussed further in section 4.2). No signals are detected beyond $0.5 \mathrm{~m}^{-1}(\lambda \leq 2 \mathrm{~m})$, which corresponds to the Nyquist frequency, defined as twice the spacing of the gridded lidar data (1m horizontal) from which the profiles are extracted.

DFT spectra show variations in surface folding characteristics at intermediate frequencies (Figure 3). Vertical fluctuations are enhanced and objectively defined by normalization to the power law of the spectral signal (Figure 3b), and, in this example, show distinct peaks at wavelengths of $40-50 \mathrm{~m}, 20 \mathrm{~m}$, and $5-10 \mathrm{~m}$ that reflect the frequency range $\left(0.025-0.2 \mathrm{~m}^{-1}\right)$ of elevated spectral density. Only the $20-\mathrm{m}$ and $5-$ to $10-\mathrm{m}$ wavelengths exceed 95\% significance and are considered dominant wavelengths. Small wavelength signals of 5-10m are present in all spectra and may represent first generation folding that is not visually discernible directly from the DTM or using profiles extracted from the DTM. DFT analyses, therefore, provide a technique to quantitatively and objectively define surface features that may be indistinguishable or present some 


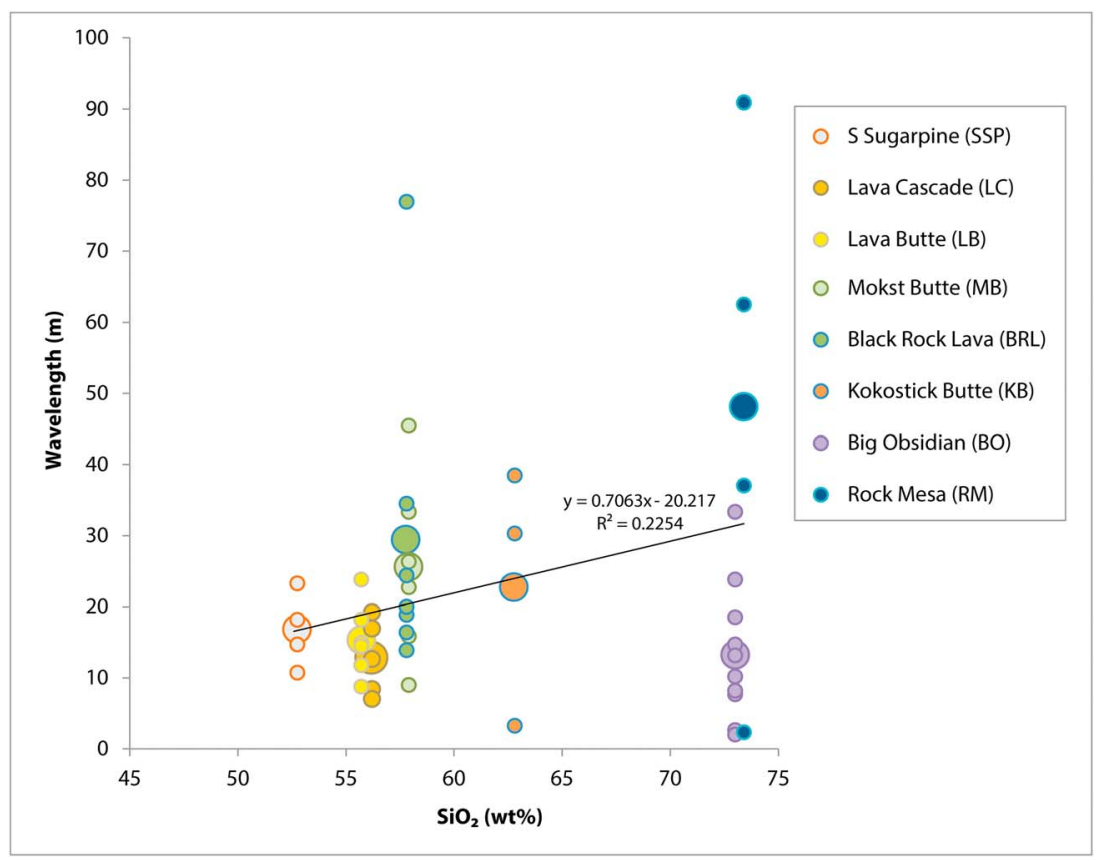

Figure 5. Dominant wavelengths of lava surface folds vs $\mathrm{SiO}_{2}$ content in weight percent. Discrete Fourier transform analyses of each lava flow segment identified multiple dominant wavelengths (small circles), likely representing multiple generations of surface folding. The large circles represent average dominant wavelengths for each flow. The black line represents the average dominant wavelength trendline, showing a general increase in dominant wavelength with $\mathrm{SiO}_{2}$.

ambiguity during manual measurements. Folds with wavelengths larger than $5-10 \mathrm{~m}$ probably represent subsequent fold generations. Multiple fold generations are common in Hawaiian pahoehoe flows and record thickening of the surface crust during flow (e.g., Fink, 1980; Fink \& Fletcher, 1978; Gregg et al., 1998).

In general, more evolved compositions (RM and BRL, but excluding $\mathrm{BO}$ ) appear to have deviations (increased spectral signatures) from their power law trendlines at longer wavelengths, and more mafic flows (SSP and LB) have deviations at intermediate and shorter wavelengths. To test this hypothesis, a simple linear regression was calculated using the average dominant wavelengths (large circles in Figure 5) fro$\mathrm{m}$ each flow to predict dominant wavelengths based on $\mathrm{SiO}_{2}$ content, resulting in a regression equation $(F[1,6]=1.746, p<0.235)$, with an $r^{2}$ of 0.225 and $95 \%$ confidence intervals (CIs) on the regression slope of $[-0.6,2.0]$. For this analysis the CI includes zero, meaning we cannot reject the null hypothesis that there is no relationship between dominant wavelength and $\mathrm{SiO}_{2}$ content. Regressions in this study are all analyses of variance where $F$ is the test statistic with the degrees of freedom for both the regression and residual reported in parentheses, respectively, and $p$ is the $p$-value indicating the significance of the test. Although there was not a statistically significant relationship when all flows were considered, dominant wavelengths range from $\sim 11-23 \mathrm{~m}$ for the most mafic lava (SSP) to 37-91m for the most felsic lava (RM). The relatively low $r^{2}$ value is likely due to a few outliers, where some lavas have lower (BO) or higher (BRL and RM) than expected average dominant wavelengths. These outliers are discussed more fully in section 4.2. Dominant wavelengths for each lava flow are listed in Table 1, and individual spectra are shown in Supporting Information 3.

\section{Discussion}

Several authors have attempted to relate surface folding to lava rheology (e.g., Fink, 1980; Fink \& Fletcher, 1978; Gregg et al., 1998). Fink and Fletcher's (1978) analysis assumes that lava viscosity decreases exponentially from the surface to a constant interior value. Minimum lava viscosity can be estimated if wavelength and crustal thickness are known. Crustal thickness is typically estimated from measured fold amplitudes or depths of surface cracks. However, fold amplitudes measured in this way may be too low if compression has 
pinched off the anticlinal trough or if the trough has been filled with debris. Additionally, in more evolved lavas the fold wavelengths may be large enough that the folding process is influenced by the base of the flow (Gregg et al., 1998), which negates Fink and Fletcher's (1978) original assumption that the flow interior has an infinite depth.

In a folding analysis of layered obsidian and pumice in rhyolitic lava, Castro and Cashman (1999) relate dominant wavelength $\left(W_{d}\right)$ to layer thickness $(T)$ and the shear viscosity ratio $\left(\mu_{l} / \mu_{m}\right)$ between layers through:

$$
W_{d}=2 \pi T\left(\frac{\mu_{l}}{6 \mu_{m}}\right)^{1 / 3}
$$

assuming that both the fold and matrix behave as Newtonian fluids (after Biot, 1961). In this relationship, dominant wavelength increases as a function of thickness and weakly, to the one-third power, with the shear viscosity ratio. Remotely one cannot determine the shear viscosity ratio between lava surfaces and their interiors. However, the wavelengths of surface folds should also scale with crustal thickness and flow viscosity, which depend on effusion rate, lava composition, and crystallinity. Therefore, increases in surface fold wavelengths should correlate with more evolved (higher viscosity) lava compositions.

Gregg et al. (1998) attempted to link surface folding with lava composition by calculating the ratio $(\Lambda)$ of second generation folds to first-generation folds. The authors determined, while $\Lambda$ generally decreased with more evolved lavas, there was significant overlap for andesite, dacite, and rhyolite lavas, disallowing a unique correlation between folding and composition. The conclusions of Gregg et al. (1998) are quite similar to our study in that we also find significant overlap in dominant surface fold wavelengths for lavas ranging from basaltic andesite to rhyolite (Figure 5).

\subsection{Dominant Wavelengths Versus Viscosities}

Using results from our DFT analyses, a comparison of dominant wavelengths with composition does not show a significant trend between average dominant wavelengths and $\mathrm{SiO}_{2}$ content (Figure 5), and has a limited goodness of fit $\left(r^{2}=0.225\right)$, due to the relatively large variability in dominant wavelengths within a given flow compared to the variability among different flows. Specifically, SSP and LB have higher average dominant wavelengths than the slightly more evolved LC; the andesite lavas, BRL and MB, have higher average and maximum dominant wavelengths than the dacitic KB; and BO has significantly lower wavelengths than the other rhyolite flow analyzed, RM.

It is important to note our data set does not represent the full range of possible lava compositions. Specifically, we did not analyze any true basalt $\left(<52 \mathrm{wt} \% \mathrm{SiO}_{2}\right)$ and do not adequately cover the daciterhyolite transition $\left(63-72 \mathrm{wt} \% \mathrm{SiO}_{2}\right)$. In an attempt to fill these gaps we have supplemented data from the literature (Figure 6), using maximum and minimum reported surface fold wavelengths and compositions from Kilauea and Mauna Loa, Hawaii; Arenal, Costa Rica; Santorini, Greece; the Chao dacite from the central Andes Altiplano-Puna Volcanic complex in Chile; and Big Glass Mountain, California (references listed in Figure 6). With this more robust data set we see that the Chao dacite, in particular, has much higher fold wavelengths than all other lava flows (Figure 6 inset), including rhyolite. Additionally, basalt has much lower fold wavelengths, ranging from a few centimeters to $10 \mathrm{~m}$. It should be noted that most basalt flows, particularly those with fold wavelengths $\leq 2 \mathrm{~m}$, cannot be identified using the airborne-derived DTMs, as in this study, but could be analyzed with higher resolution DTMs derived from terrestrial laser scanning or through manual measurements. Andesite and rhyolite surface fold measurements from the literature appear to have similar values to those produced by DFT analyses in this study.

Considering the fold wavelengths from this study and the literature, there may be a general nonlinear trend showing dominant wavelengths increasing with $\mathrm{SiO}_{2}$ content. However, the deviations from this nonlinear trend, especially for dacite and rhyolite, and the low goodness of fit from our DFT-derived average dominant wavelengths (Figure 5), suggest the relationship between fold wavelength and $\mathrm{SiO}_{2}$ content is not a direct correlation. Instead, plotting average dominant wavelengths against calculated viscosities (Figure 7a; calculated viscosities listed in Table 1$)$ results in an improved simple linear regression equation $(F[1,5]=10.71$, $p<0.022$ ), with an $r^{2}$ of 0.682 and $95 \%$ CI $\left[6.6 \times 10^{-7}, 5.6 \times 10^{-6}\right]$. Since the CI does not include zero, we reject 


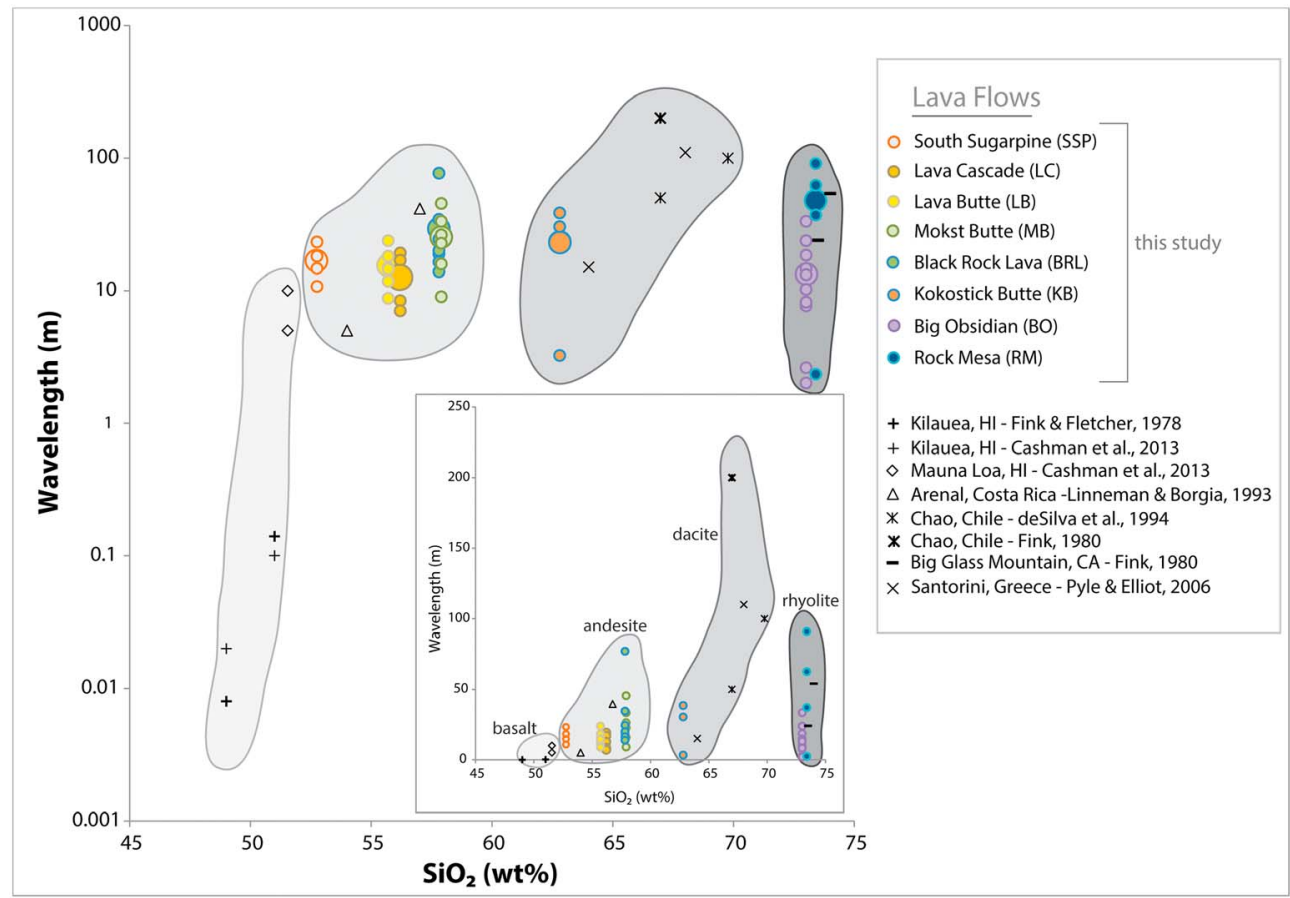

Figure 6. Dominant wavelengths determined in this study, plotted on a log plot with others from the literature (references

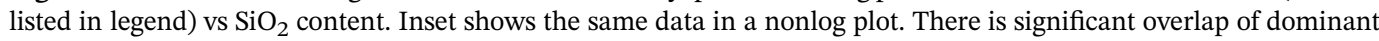
wavelengths for lavas ranging from basalt to rhyolite, particularly for basaltic andesite and andesite lavas. However, note the much lower dominant wavelengths of basalt from Kilauea and the extremely high fold wavelengths of the Chao dacite.

the null hypothesis and find that there is a positive trend. The quality of the regression (i.e., the value of $r^{2}$ ) is improved if we expand the range of viscosities by supplementing the data set with average fold wavelengths and viscosities from the Chao dacite (Desilva et al., 1994) and basalt from Mauna Loa and Kilauea (H. Pinkerton \& Stevenson, 1992), producing a simple linear regression $\left(F[1,8]=51.64, p<9.37 \times 10^{-5}\right)$, with an $r^{2}$ of 0.866 and $95 \%$ CI $\left[1.4 \times 10^{-10}, 2.7 \times 10^{-10}\right]$ (Figure $7 \mathrm{~b}$ ). This analysis also has a CI that does not include zero, allowing us to reject the null hypothesis and state there is a positive correlation between dominant wavelength and viscosity. Overall, we suggest that fold wavelength and composition have an indirect correlation that is only partially due to $\mathrm{SiO}_{2}$ content. A more direct relationship is found between fold wavelength and effective viscosity, controlled, in part, by composition, but also crystallinity.

Although melt viscosity increases as compositions become more evolved, effective viscosity is also strongly influenced by the crystal content of the lava. For example, obsidian flows by definition typically have low crystallinities. In contrast, $\mathrm{H}_{2} \mathrm{O}$-rich andesite and dacite lavas often have high crystallinities due to extensive decompression-driven crystallization, while rhyolitic lavas show very little decompression crystallization (K. Cashman \& Rust, 2016). The effects of crystallization are twofold: addition of solid particles increases the effective viscosity (e.g., Costa, 2005) and crystallization increases the silica content (and viscosity) of the remaining matrix melt. Thus, andesitic lavas may have matrix glass compositions that approach lowSi rhyolite, while dacite lavas often have high-Si rhyolite matrix melt compositions (e.g., K. Cashman \& Blundy, 2000).

The influence of crystallinity on effective viscosity is observed in Figure 7 as deviations from the predicted order (based purely on composition) of lava flow viscosities. Effective viscosity, controlled largely by crystallinity, does not simply increase with $\mathrm{SiO}_{2}$ (Table 1). Specifically, LB has a slightly less evolved composition relative to LC and MB but has an effective viscosity an order of magnitude higher than LC and almost twice that of MB, due to differences in crystallinity of $44 \%$ and $17 \%$, respectively. BRL has a similar composition to MB but has viscosities over 2 times greater due to $10 \%$ greater crystallinity. BO and RM are very similar compositionally, but $\mathrm{RM}$ has $>7.5 \times 10^{6} \mathrm{~Pa}$ s higher viscosity, likely due to the $\sim 20 \%$ greater crystallinity. 

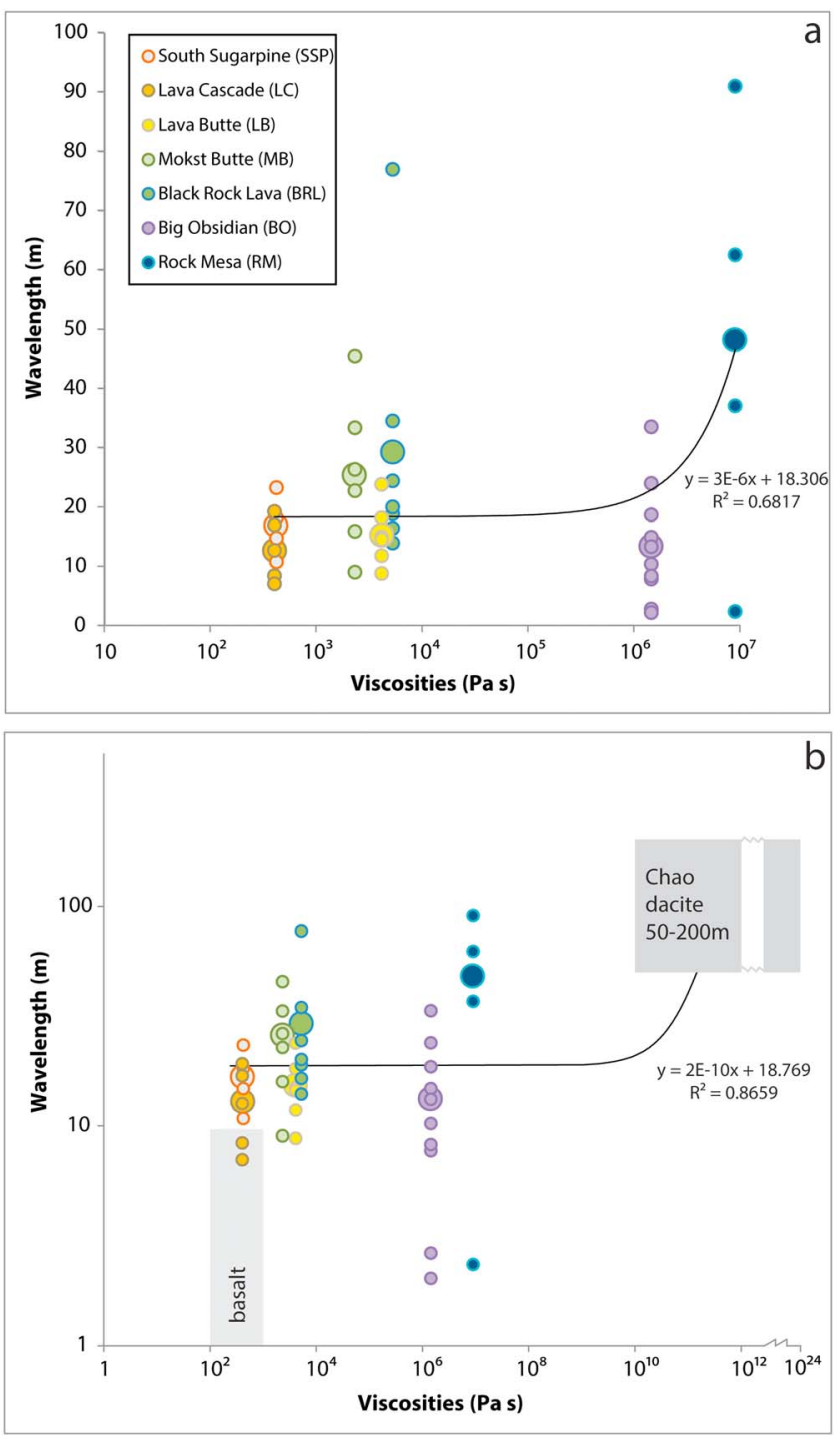

Figure 7. (a) Discrete Fourier transform dominant wavelengths vs calculated effective viscosities showing a generally increasing trend, with only a couple of exceptions (see section 4.1). Big Obsidian flow, in particular, has much lower dominant wavelengths than expected for a rhyolite flow with high viscosity. (b) The discrete Fourier transform dominant fold wavelengths vs viscosity on a log-log plot. The shaded regions represent ranges of fold wavelengths and viscosities reported in the literature for basalt (light gray) and the Chao dacite, Chile (dark gray).
Similarly, the extreme fold wavelengths and flow front thicknesses $(<400 \mathrm{~m})$ of the Chao lava flow likely reflect dacitic lava with crystallinities of $40-60 \%$ creating viscosities ranging from $10^{10}-10^{12} \mathrm{~Pa}$ s for internal plastic viscosities to $10^{15}-10^{24} \mathrm{~Pa}$ s for surface viscosities (Desilva et al., 1994; Figure 7b). Basaltic lava flows, with dominant fold wavelengths on the order of centimeters (J. H. Fink \& Fletcher, 1978) to meters (K. V. Cashman et al., 2013; light gray region- Figure 7b), have a large range in viscosity $\left(10^{2}-10^{5} \mathrm{~Pa} \mathrm{~s}\right)$ that is strongly influenced by crystallinity (e.g., Harris \& Allen, 2008; Lipman \& Banks, 1987).

In this study, each lava flow exhibits a range of dominant surface fold wavelengths, which likely represent multiple generations of folding due to fluctuations in viscosity during emplacement. The viscosity of a lava flow increases during emplacement as the lava cools, solidifies forming surface crust, and crystallinity increases. This process is important in the development of surface folds, and, particularly, in multiple fold generations as viscosity increases and surface crust thickens (e.g., J. H. Fink \& Fletcher, 1978). The surface folds detected with our DFT analyses likely represent a range of viscosities, with larger fold wavelengths representing greater viscosities and temporally younger (occurring later in eruption sequence) fold generations, due to greater viscosities and thicker crust. Therefore, the maximum dominant wavelengths for each flow should represent the maximum viscosity that the lava flow surface crust experienced. However, as each of these flows was not observed and measured syn-emplacement, we cannot determine the total range of viscosities that influenced formation of surface folding. We have presented lava viscosities as single (minimum) values, which should best represent the average or smaller dominant wavelengths. Additionally, although the maximum dominant wavelength for each flow generally increases with effective viscosity, with the exceptions of LC, LB, and BO (Figure 7), the relationship between max dominant fold wavelength and viscosity has a linear regression of $(F[1,5]=4.71, p<0.082)$, with an $r^{2}$ of 0.485 , producing a weaker correlation with viscosity than average dominant wavelengths.

While the average dominant wavelengths vs viscosity provides a reasonable goodness of fit and is statistically significant, it is a somewhat weak correlation and we are not completely confident in using this correlation for the purposes of prediction due to gaps in our current data set. Additional DFT analyses of lavas with viscosities of $10^{3}->10^{12} \mathrm{~Pa} \mathrm{~s}$ are needed to create a more robust data set from which a numeric model can be produced to remotely characterize the viscosity of lava flows strictly from their dominant fold wavelengths. This will include analyzing lava flows ranging from basaltic andesite to rhyolite in composition but also requires analysis of lava flows of similar compositions, but over a range of crystallinities, which will allow us to more fully determine the influence of crystallinity on viscosity and resulting dominant fold wavelengths.

\subsection{Eruption Conditions}

In addition to composition and viscosity, the range of fold wavelengths observed for an individual flow is likely influenced by effusion rate and eruption temperature. Eruption rate will influence the rate of crust formation as well as flow velocity differentials between the lava crust (margins and surface) and flow interior. The effect of effusion rates on surface folding is poorly understood, as high eruption rates will create greater instabilities between fluid interiors and forming crust, but will also transport surface crust a greater distance before and during solidification. The rate of lava crust formation is largely controlled by eruption 
temperature and cooling rate. For example, a hot, incandescent basaltic flow will not have a solidified crust until cooling further from the vent, while a cooler, more evolved flow will emerge with a surface crust that exhibits a yield strength and could experience greater microlite growth.

Eruption conditions appear to affect the dominant wavelengths of flows analyzed in this study. The basaltic andesite LB has a calculated viscosity bracketed by the andesite lavas MB and BRL, but with lower maximum and average dominant wavelengths, possibly due to higher eruption temperatures. Alternatively, MB and BRL may have higher than expected dominant wavelengths, based on viscosity, which could be due to cooler eruption temperature and perhaps greater microlite crystallization within the conduit and syn-eruption. BO has dominant wavelengths lower than expected, based on its viscosity, and significantly lower than RM, which cannot easily be explained by variations in eruption conditions. However, obsidian flows, including BO, are commonly composed of alternating layers of obsidian, vent-facies rhyolite, finely vesicular pumice, and coarsely vesicular pumice (Castro et al., 2002; Manley \& Fink, 1987). The pumiceous layers are much more compressible than obsidian and could be deformed during emplacement affecting the resulting surface fold wavelengths, allowing more compression than in nonpumiceous lava, potentially narrowing the distance between waveform crests. Castro and Cashman (1999) found that the relative thickness between pumice and obsidian layers governed the style of folding and fold wavelengths and that local flattening and extension were often observed in pumice layers around fold hinges. Obsidian flows with significant pumiceous layers of varying thicknesses may have somewhat unpredictable dominant fold wavelengths. If BO is removed from the linear regression of average dominant wavelengths from our DFT analysis (Figure 7a), the correlation is slightly improved; $(F[1,4]=13.38, p<0.0 .021)$, with an $r^{2}$ of 0.77 .

\subsection{Lava Flow Roughness}

The variation observed in the spectral power of lava profiles is greatest at intermediate and low frequencies (intermediate and high $\lambda$ ) but also varies at high frequencies (low $\lambda$ ). Since all lidar data were collected with similar spatial point densities and all DTMs were gridded at 1-m horizontal resolution, we suspect that the power spectra are recognizing natural features, rather than inherent variability in the lidar data itself, even at the high frequencies recognized. To examine the high frequency variability, we calculated lava flow roughness on all detrended lava profiles using a root-mean-square height (RMSH) analysis (after Shepard et al., 2001).

$$
\mathrm{RMSH}=\left[\frac{1}{n-1} \sum_{i=1}^{n}\left(z\left(x_{i}\right)-\bar{z}\right)^{2}\right]^{1 / 2}
$$

In this analysis, $n$ is the number of sample points and $z\left(x_{i}\right)$ is the height of each point $\left(x_{i}\right)$ above or below the mean elevation of the detrended profile $(\bar{z})$. The RMSH quantifies fluctuations (both positive and negative) from the mean $(\bar{z})$, providing a roughness value comparable between lava flows. Unlike the DFT, the RMSH does not parse the contributions of individual wavelength features to the overall topographic variance. The calculated roughness, therefore, may include large block sizes or clusters of blocks, surface folds (peaks and troughs), extensional cracks, and small changes in slope not corrected during detrending.

Dominant wavelengths of surface folds when plotted against lava surface roughness produce a simple linear regression $\left(F[1,6]=23.43, p<0.003\right.$ ), with an $r^{2}$ of 0.796 (Figure $8 \mathrm{a}$ ). This suggests that longer wavelength folds tend to be higher in amplitude than shorter wavelength ones, thereby contributing more to the RMSH. This is consistent with the power law decrease observed in all lava flow power spectra. LB and BO both have higher roughnesses than expected, suggesting that they may have larger block sizes, or other influencing factors, than lavas with similar dominant fold wavelengths.

In Figure 8b we have plotted the power law trendlines for the power spectral densities shown in Figure 4, but only showing the high frequency end of the spectra (i.e., wavelengths shorter than $10 \mathrm{~m}$ ). With the exception of $\mathrm{KB}$ and $\mathrm{BO}$, the highest frequency signals (right end of trendlines) increase power spectral densities from one lava flow to the next in the same order that roughness increases in Figure 8a (SSP-LC-MB-LB-BRL-RM). This is expected as our DFT analysis is measuring the topographic variance (standard deviation squared) as a function of individual wavelengths. The total sum of the DFT periodogram equals the total variance of the profile being analyzed. The RMSH analysis is essentially the standard deviation of height (=sqrt [variance]), 


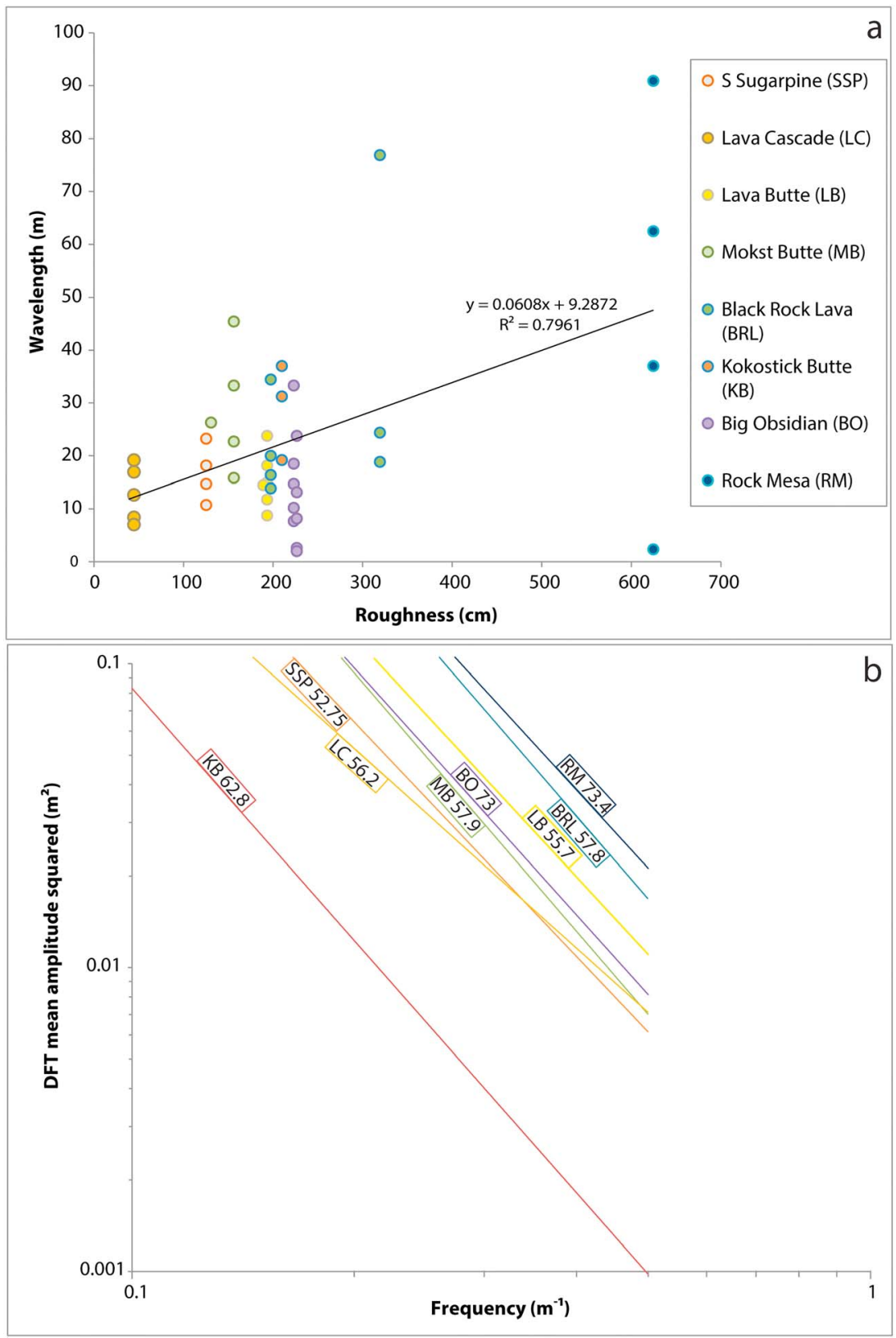

Figure 8. (a) Dominant fold wavelengths vs calculated lava profile roughness. Surface folding appears to strongly impact the overall roughness of each lava profile generating a positive correlation. (b) Trendlines for each discrete Fourier transform (DFT) power spectral density from Figure 4 are plotted. Power spectral densities at the highest frequencies increase with increased roughness with only two exceptions: $\mathrm{KB}$ and $\mathrm{BO}$ (see section 4.2 for discussion).

creating a tight coupling between RMSH and our DFT power spectra, with a few differences due to the DFT being a windowed analysis. The high frequency power spectral densities of $\mathrm{KB}$ and $\mathrm{BO}$ are lower than expected due to other influencing factors. KB has a much lower PSD at high frequencies than all other flows but has similar PSD at low frequencies (Figure 4). This is likely due to its partial covering of Mazama ash, which was deposited during the catastrophic eruption that formed Crater Lake, filling in troughs between surface fold ridges and, perhaps between lava blocks. The partial covering and smoothing of $\mathrm{KB}$ is likely decreasing its original surface roughness and reducing its PSD at high frequencies. $\mathrm{BO}$ has been consistently different from the other flows in all of our analyses. We suggest that the compressible pumice layers of $\mathrm{BO}$ alter the dynamics of surface crust formation and surface 
folding significantly, and, therefore, effect roughness and PSD. The implications from our analyses is that fold wavelength, total roughness (from the RMSH), and high-frequency roughness (from the DFT) all covary and generally increase with calculated viscosity, which implies that more viscous flows not only produce longer fold wavelengths but also produce rougher surfaces over the full range of spatial frequencies.

\section{Conclusions}

In this study we have shown that DFT analyses can be used on lava surface profiles to extract dominant fold wavelengths, a technique that has been rarely used on volcanic landforms. For each lava flow analyzed at least three dominant surface folds were identified, suggesting that the DFT analyses detect multiple fold generations. Multiple-fold generations for each flow likely represent progressive thickening of the lava crust and increased viscosity as the flow advances and evolves, as seen in basaltic flows in Hawaii. In this study we found that average dominant wavelengths did not increase with more evolved composition but did increase with calculated lava viscosity, with only a few exceptions. However, the ranges of dominant wavelengths show significant overlap for most lava flows ranging from basaltic andesite to rhyolite. Specifically, the 10- to 20-m dominant wavelengths are present in nearly all lavas (missing only from $\mathrm{KB}$, likely due to its coating of Mazama ash) and likely represent early fold generations. Because our calculations presented minimum viscosities, our analyses seem to best represent the average dominant viscosities, which have the most statistically significant correlation. However, the maximum dominant wavelength for each flow may be the most representative as they indicate the final and maximum viscosity and crust thickness achieved. Additionally, larger dominant wavelengths are often still apparent even with some sedimentation on the lava and are detectable with DFT analyses, even though the overall power spectra (and overall roughness) will likely be reduced relative to a fresh, uncovered flow. Another viscosity calculation that better represents maximum viscosity of the lava may be needed for future studies.

In our analyses we observed a few exceptions to the fold wavelength vs viscosity trend, which include variations in fold wavelength from lavas of similar composition or viscosity and, for most flows, may be explained by differences in eruption temperature, eruption rates, or emplacement conditions. Analyses of a larger number of flows and a wider range of lava compositions and viscosities may allow us to determine typical ranges of surface fold wavelengths for a given composition or viscosity. Obsidian flows, however, may be more difficult to remotely characterize as BO has significantly lower dominant wavelengths than other rhyolite lavas, likely due to compressible pumice layers within the obsidian that altered the formation of surface folds. Therefore, obsidian flows with significant pumice contents may require an alternative means of remote characterization. It is also possible the relatively low dominant wavelengths and high surface roughness of $\mathrm{BO}$ may suggest a signature for obsidian flows with significant pumice layers and low crystallinity. More obsidian flows will need to be analyzed by DFT to determine if the low dominant fold wavelengths detected at $\mathrm{BO}$ is typical for all obsidian flows.

We have also shown that DFT power spectral densities (particularly at the highest frequencies) correlate with lava profile roughness and that dominant fold wavelength is closely related to lava surface roughness. Due to the resolution of the airborne lidar data used in this study and the nature of DFT analyses, we are unable to directly measure lava block sizes. However, the highest frequencies $\left(>0.2 \mathrm{~m}^{-1}\right)$ that produced the lowest power spectral densities may represent differences in relative block sizes. All lava profiles analyzed have strong deviations from the trendline at frequencies $>0.2 \mathrm{~m}^{-1}$ (Figure 4 and Supporting Information S3), suggesting a natural signal that may represent first generation folds or, perhaps, relate to block size. The most evolved lavas (KB, BO, and RM) have deviations with $95 \%$ confidence at frequencies $>0.2 \mathrm{~m}^{-1}$ that have been reported as dominant wavelengths in this study. These 2- to 3-m dominant wavelengths are of a significantly different scale than the other dominant wavelengths detected ( $>30 \mathrm{~m}$ for KB and RM), suggesting that they may instead represent large block sizes or block clusters. These high-frequency, low PSD signatures may provide a means to remotely estimate block sizes of evolved lavas in extremely remote regions and extraterrestrial environments.

A primary goal of this project was to determine a numeric correlation between dominant wavelengths of surface folds and lava rheology that would allow remote characterization of lava flows. Although the average dominant wavelengths determined in this study produce a statistically significant positive linear 
regression $\left(r^{2}=0.68\right)$, we do not feel confident producing a numeric model defining this relationship due to the limited data set and the significant overlap of dominant wavelengths between flows. To produce a viable model that can be used to remotely characterize the rheology (viscosity) of lava flows, a more robust data set is needed, specifically including DFT-derived analyses of basalt and dacite. With lidar DTMs becoming increasingly available, we suspect that the appropriate data sets and lava flows will soon be accessible. In this study we have shown that DFT analyses can be used to quantitatively characterize surface morphologies, such as dominant surface folds, of lava flows, which can then be compared to lava rheology. DFT analyses provide a versatile tool for remotely characterizing lava flows with significant implications for possible future analyses of volcanic terrains on Earth and other extraterrestrial bodies.

\section{References}

Acknowledgments
Funding for this project was provided by the PASSHE Faculty Professional Development Council and through an IUP University Senate Research Committee award. Lidar data used in this study were acquired from the Oregon Lidar Consortium (https:// www.oregongeology.org/lidar/). Lava elevation profiles used in this study and the Matlab code used to extract Discrete Fourier Transform analyses have been provided in the supporting information. The authors declare no conflicts of interest or competing financial interests.

Applegarth, L., Pinkerton, H., James, M. R., \& Calvari, S. (2010). Lava flow superposition: The reactivation of flow units in compound'a'ā flows. Journal of Volcanology and Geothermal Research, 194(4), 100-106. https://doi.org/10.1016/j. jvolgeores.2010.05.001

Asimow, P. D., \& Ghiorso, M. S. (1998). Algorithmic modifications extending MELTS to calculate subsolidus phase relations. American Mineralogist, 83(9-10), 1127-1132. https://doi.org/10.2138/am-1998-9-1022

Biot, M. A. (1961). Theory of folding of stratified viscoelastic media and its implications in tectonics and orogenesis. Geological Society of America Bulletin, 72(11), 1595-1620. https://doi.org/10.1130/0016-7606(1961)72[1595:TOFOSV]2.0.CO;2

Blundy, J., \& Cashman, K. (2005). Rapid decompression-driven crystallization recorded by melt inclusions from Mount St. Helens volcano. Geology, 33(10), 793-796. https://doi.org/10.1130/G21668.1

Booth, A. M., Roering, J. J., \& Perron, J. T. (2009). Automated landslide mapping using spectral analysis and high-resolution topographic data: Puget Sound lowlands, Washington, and Portland Hills, Oregon. Geomorphology, 109(3-4), 132-147. https://doi.org/10.1016/j. geomorph.2009.02.027

Borgia, A., \& Linneman, S. (1990). On the mechanisms of lava flow emplacement and volcano growth: Arenal, Costa Rica. In Lava Flows and Domes, (pp. 208-243). Berlin, Heidelberg: Springer.
Borgia, A., Linneman, S., Spencer, D., Morales, L. D., \& Andre, J. B. (1983). Dynamics of lava flow fronts, Arenal volcano, Costa Rica. Journal of Volcanology and Geothermal Research, 19(3-4), 303-329. https://doi.org/10.1016/0377-0273(83)90116-6

Calvari, S., Neri, M., \& Pinkerton, H. (2003). Effusion rate estimations during the 1999 summit eruption on Mount Etna, and growth of two distinct lava flow fields. Journal of Volcanology and Geothermal Research, 119(1-4), 107-123. https://doi.org/10.1016/S03770273(02)00308-6

Caricchi, L., Burlini, L., Ulmer, P., Gerya, T., Vassalli, M., \& Papale, P. (2007). Non-Newtonian rheology of crystal-bearing magmas and implications for magma ascent dynamics. Earth and Planetary Science Letters, 264(3-4), 402-419. https://doi.org/10.1016/j. epsl.2007.09.032

Cashman, K., \& Blundy, J. (2000). Degassing and crystallization of ascending andesite and dacite. Philosophical Transactions of the Royal Society a-Mathematical Physical and Engineering Sciences, 358(1770), 1487-1513. https://doi.org/10.1098/rsta.2000.0600

Cashman, K., \& Rust, A. (2016). Volcanic ash: Generation and spatial variations. In Volcanic Ash: Hazard Observation. Amsterdam, Netherlands: Elsevier.

Cashman, K. V., Soule, S. A., Mackey, B. H., Deligne, N. I., Deardorff, N. D., \& Dietterich, H. R. (2013). How lava flows: New insights from applications of lidar technologies to lava flow studies. Geosphere, 9(6), 1664-1680. https://doi.org/10.1130/Ges00706.1

Cashman, K. V., \& Sparks, R. S. J. (2013). How volcanoes work: A 25 year perspective. Geological Society of America Bulletin, 125(5-6), 664-690. https://doi.org/10.1130/B30720.1

Castro, J., \& Cashman, K. V. (1999). Constraints on rheology of obsidian lavas based on mesoscopic folds. Journal of Structural Geology, 21(7), 807-819.

Castro, J., Cashman, K., Joslin, N., \& Olmsted, B. (2002). Structural origin of large gas cavities in the Big Obsidian Flow, Newberry Volcano. Journal of Volcanology and Geothermal Research, 114(3-4), 313-330. https://doi.org/10.1016/S0377-0273(01)00296-7

Cigolini, C., Borgia, A., \& Casertano, L. (1984). Intra-crater activity, aa-block lava, viscosity and flow dynamics: Arenal Volcano, Costa Rica Journal of Volcanology and Geothermal Research, 20(1-2), 155-176. https://doi.org/10.1016/0377-0273(84)90072-6

Costa, A. (2005). Viscosity of high crystal content melts: Dependence on solid fraction. Geophysical Research Letters, 32, L22308. https://doi. org/10.1029/2005gl024303

Costa, A., Caricchi, L., \& Bagdassarov, N. (2009). A model for the rheology of particle-bearing suspensions and partially molten rocks. Geochemistry, Geophysics, Geosystems, 10, Q03010. https://doi.org/10.1029/2008gc002138

Deardorff, N. D., \& Cashman, K. V. (2012). Emplacement conditions of the c. 1,600-year bp Collier Cone lava flow, Oregon: a LiDAR investigation. Bulletin of Volcanology, 74(9), 2051-2066. https://doi.org/10.1007/s00445-012-0650-9

Desilva, S. L., Self, S., Francis, P. W., Drake, R. E., \& Ramirez, C. (1994). Effusive Silicic Volcanism in the Central Andes-The Chao Dacite and Other Young Lavas of the Altiplano-Puna Volcanic Complex. Journal of Geophysical Research, 99(B9), 17,805-17,825. https://doi. org/10.1029/94jb00652

Fierstein, J., Hildreth, W., \& Calvert, A. T. (2011). Eruptive history of South Sister, Oregon Cascades. Journal of Volcanology and Geothermal Research, 207(3-4), 145-179. https://doi.org/10.1016/j.jvolgeores.2011.06.003

Fink, J. (1980). Surface folding and viscosity of rhyolite flows. Geology, 8(5), 250-254. https://doi.org/10.1130/0091-7613(1980)8<250: SFAVOR $>2.0 . \mathrm{CO} ; 2$

Fink, J. H., \& Fletcher, R. C. (1978). Ropy pahoehoe: Surface folding of a viscous fluid. Journal of Volcanology and Geothermal Research, 4(1-2), 151-170. https://doi.org/10.1016/0377-0273(78)90034-3

Gay, E. C., Nelson, P. A., \& Armstrong, W. P. (1969). Flow properties of suspensions with high solids concentration. Aiche Journal, 15(6), 815-822. https://doi.org/10.1002/aic.690150606

Geschwind, C.-H., \& Rutherford, M. J. (1995). Crystallization of microlites during magma ascent: the fluid mechanics of 1980-1986 eruptions at Mount St Helens. Bulletin of Volcanology, 57(5), 356-370. https://doi.org/10.1007/BF00301293 
Ghiorso, M. S., \& Sack, R. O. (1995). Chemical mass-transfer in magmatic processes.4. A revised and internally consistent thermodynamic model for the interpolation and extrapolation of liquid-solid equilibria in magmatic systems at elevated-temperatures and pressures. Contributions to Mineralogy and Petrology, 119(2-3), 197-212. https://doi.org/10.1007/Bf00307281

Giordano, D., Russell, J. K., \& Dingwell, D. B. (2008). Viscosity of magmatic liquids: A model. Earth and Planetary Science Letters, 271(1-4), 123-134. https://doi.org/10.1016/j.epsl.2008.03.038

Gregg, T. K., Fink, J. H., \& Griffiths, R. W. (1998). Formation of multiple fold generations on lava flow surfaces: Influence of strain rate, cooling rate, and lava composition. Journal of Volcanology and Geothermal Research, 80(3-4), 281-292. https://doi.org/10.1016/S03770273(97)00048-6

Griffiths, R. (2000). The dynamics of lava flows. Annual Review of Fluid Mechanics, 32(1), 477-518. https://doi.org/10.1146/annurev. fluid.32.1.477

Guest, J., Kilburn, C., Pinkerton, H., \& Duncan, A. (1987). The evolution of lava flow-fields: observations of the 1981 and 1983 eruptions of Mount Etna, Sicily. Bulletin of Volcanology, 49(3), 527-540. https://doi.org/10.1007/BF01080447

Hammer, J. E., \& Rutherford, M. J. (2002). An experimental study of the kinetics of decompression-induced crystallization in silicic melt. Journal of Geophysical Research, 107(B1), 2021. https://doi.org/10.1029/2001JB000281

Harris, A. J. L., \& Allen, J. S. (2008). One-, two- and three-phase viscosity treatments for basaltic lava flows. Journal of Geophysical Research, 113, B09212. https://doi.org/10.1029/2007JB005035

Harris, A. J. L., Rose, W. I., \& Flynn, L. P. (2003). Temporal trends in lava dome extrusion at Santiaguito 1922-2000. Bulletin of Volcanology, 65(2), 77-89. https://doi.org/10.1007/s00445-002-0243-0

Hon, K., Kauahikaua, J., Denlinger, R., \& Mackay, K. (1994). Emplacement and inflation of pahoehoe sheet flows: observations and measurements of active lava flows on Kilauea Volcano, Hawaii. Geological Society of America Bulletin, 106(3), 351-370. https://doi.org/ 10.1130/0016-7606(1994)106<0351:EAIOPS > 2.3.CO;2

Jensen, R. A., Donnelly-Nolan, J. M., \& Mckay, D. (2009). A field guide to Newberry Volcano, Oregon. In Volcanoes to vineyards: geologic field trips through the dynamic landscape of the Pacific Northwest. Field Guide (Vol. 15, pp. 53-79). Boulder, CO: Geological Society of America.

Kauahikaua, J., Cashman, K. V., Mattox, T. N., Heliker, C. C., Hon, K. A., Mangan, M. T., \& Thornber, C. R. (1998). Observations on basaltic lava streams in tubes from Kilauea Volcano, island of Hawai'i. Journal of Geophysical Research, 103(B11), 27,303-27,323. https://doi.org/10.1029/97JB03576

Lipman, P., \& Banks, N. (1987). AA flow dynamics, Mauna Loa 1984, U.S. Geological Survey Professional Paper, (Vol. 1350, pp. 1527-1567). Washington, DC: American Geophysical Union.

MacLeod, N. S., \& Sherrod, D. R. (1992). Reconnaissance geologic map of the west half of the Crescent 1 degree by 2 degrees Quadrangle, central Oregon. Denver, CO: U.S. Geological Survey.

MacLeod, N. S., Sherrod, D. R., Chitwood, L. A., \& Jensen, R. A. (1995). Geologic map of Newberry Volcano, Deschutes, Klamath, and Lake Counties, Oregon. Denver, CO: U.S. Geological Survey.

Mader, H. M., Llewellin, E. W., \& Mueller, S. P. (2013). The rheology of two-phase magmas: A review and analysis. Journal of Volcanology and Geothermal Research, 257, 135-158. https://doi.org/10.1016/j.jvolgeores.2013.02.014

Major, J. J., \& Lara, L. E. (2013). Overview of Chaitén Volcano, Chile, and its 2008-2009 eruption. Andean Geology, 40(2), 196-215. https://doi.org/10.5027/andgeoV40n2-a01

Manley, C. R., \& Fink, J. H. (1987). Internal textures of rhyolite flows as revealed by research drilling. Geology, 15(6), 549-552. https:// doi.org/10.1130/0091-7613(1987)15<549:ITORFA >2.0.CO;2

Marsh, B. D. (1981). On the crystallinity, probability of occurrence, and rheology of lava and magma. Contributions to Mineralogy and Petrology, 78(1), 85-98. https://doi.org/10.1007/Bf00371146

Mckay, D., Donnelly-Nolan, J. M., Jensen, R. A., \& Champion, D. E. (2009). The post-Mazama northwest rift zone eruption at Newberry Volcano, Oregon Field Guides, 15, 91-110. https://doi.org/10.1130/2009.fld015(05)

Murase, T., \& McBirney, A. R. (1973). Properties of some common igneous rocks and their melts at high temperatures. Geological Society of America Bulletin, 84(11), 3563-3592.

Naranjo, J., Sparks, R., Stasiuk, M., Moreno, H., \& Ablay, G. (1992). Morphological, structural and textural variations in the 1988-1990 andesite lava of Lonquimay Volcano, Chile. Geological Magazine, 129(6), 657-678. https://doi.org/10.1017/S0016756800008426

Pallister, J. S., Diefenbach, A. K., Burton, W. C., Muñoz, J., Griswold, J. P., Lara, L. E., et al. (2013). The Chaitén rhyolite lava dome: Eruption sequence, lava dome volumes, rapid effusion rates and source of the rhyolite magma. Andean Geology, 40(2). https://doi.org/ 10.5027/andgeoV40n2-a06

Perron, J. T., Kirchner, J. W., \& Dietrich, W. E. (2008). Spectral signatures of characteristic spatial scales and nonfractal structure in landscapes. Journal of Geophysical Research, 113, F04003. https://doi.org/10.1029/2007JF000866

Pinkerton, H., \& Stevenson, R. J. (1992). Methods of determining the rheological properties of magmas at sub-liquidus temperatures Journal of Volcanology and Geothermal Research, 53(1-4), 47-66. https://doi.org/10.1016/0377-0273(92)90073-M

Pinkerton, H., \& Wilson, L. (1994). Factors controlling the lengths of channel-fed lava flows. Bulletin of Volcanology, 56(2), 108-120. https:// doi.org/10.1007/BF00304106

Priestley, M. B. (1981). Spectral analysis and time series (Vol. 1). London: Academic Press.

Pyle, D. M., \& Elliott, J. R. (2006). Quantitative morphology, recent evolution, and future activity of the Kameni Islands volcano, Santorini, Greece. Geosphere, 2(5), 253-268. https://doi.org/10.1130/GES00028.1

Rayner, J. N., \& Golledge, R. G. (1972). Spectral analysis of settlement patterns in diverse physical and economic environments. Environment and Planning, 4(3), 347-371. https://doi.org/10.1068/a040347

Rose, W. (1973). Pattern and mechanism of volcanic activity at the Santiaguito volcanic dome, Guatemala. Bulletin of Volcanology, 37(1), 73-94. https://doi.org/10.1007/BF02596881

Scott, W. E. (1987). Holocene rhyodacite eruptions on the flanks of South Sister volcano, Oregon. In The emplacement of silicic domes and lava flows. Geological Society of America Special Paper 212 (pp. 35-53. Boulder, CO: Geological Society of America.

Shaw, H. R. (1972). Viscosities of magmatic silicate liquids-Empirical method of prediction. American Journal of Science, 272(9), 870-893. https://doi.org/10.2475/ajs.272.9.870

Shepard, M. K., Campbell, B. A., Bulmer, M. H., Farr, T. G., Gaddis, L. R., \& Plaut, J. J. (2001). The roughness of natural terrain: A planetary and remote sensing perspective. Journal of Geophysical Research, 106(E12), 32,777-32,795. https://doi.org/10.1029/ 2000je001429

Sherrod, D. R., Scott, W. E., \& Stauffer, P. H. (2008). A volcano rekindled: The renewed eruption of Mount St. Helens, 2004-2006, U.S. Geological Survey Professional Paper 1750 (pp. 2330-7102). Reston, VA: U.S. Geological Survey. 
Sherrod, D. R., Taylor, E. M., Ferns, M. L., Scott, W. E., \& Smith, G. A. (2004). Geologic map of the Bend 30-x 60-minute quadrangle, central Oregon. Washington: US Geological Survey.

Slim, A., Balmforth, N., Craster, R., \& Miller, J. (2009). Surface wrinkling of a channelized flow. Paper presented at the Proceedings of the Royal Society ofLondon A: Mathematical, Physical and Engineering Sciences.

Smith, J. V., \& Houston, E. C. (1994). Folds produced by gravity spreading of a banded rhyolite lava flow. Journal of Volcanology and Geothermal Research, 63(1-2), 89-94. https://doi.org/10.1016/0377-0273(94)90019-1

Soule, S. A., \& Cashman, K. V. (2005). Shear rate dependence of the pahoehoe-to-'a'a transition: Analog experiments. Geology, 33(5), 361-364. https://doi.org/10.1130/G21269.1

Swanson, D., \& Holcomb, R. (1990). Regularities in growth of the Mount St. Helens dacite dome, 1980-1986. In Lava Flows and Domes: Emplacement Mechanisms and Hazard Implications, (pp. 3-24). Berlin, Heidelberg: Springer.

Torrence, C., \& Compo, G. P. (1998). A practical guide to wavelet analysis. Bulletin of the American Meteorological Society, 79(1), 61-78. https://doi.org/10.1175/1520-0477(1998)079<0061:Apgtwa>2.0.Co;2

Tuffen, H., James, M. R., Castro, J. M., \& Schipper, C. I. (2013). Exceptional mobility of an advancing rhyolitic obsidian flow at Cordón Caulle volcano in Chile. Nature Communications, 4(1). https://doi.org/10.1038/ncomms3709

Vallance, J. W., Schneider, D. J., \& Schilling, S. P. (2008). Growth of the 2004-2006 lava-dome complex at Mount St. Helens, Washington. A Volcano Rekindled, 2004-2006.

Wadge, G., Walker, G., \& Guest, J. (1975). The output of the Etna volcano. Nature, 255(5507), 385-387. https://doi.org/10.1038/255385a0

Walker, G. (1971). Compound and simple lava flows and flood basalts. Bulletin Volcanologique, 35(3), 579-590. https://doi.org/10.1007/ BF02596829 